\title{
A tunable L-arabinose-inducible expression plasmid for the acetic acid bacterium Gluconobacter oxydans
}

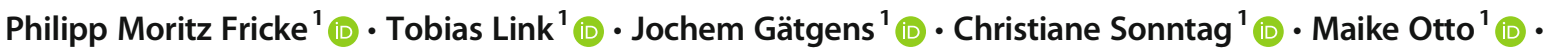 \\ Michael Bott ${ }^{1}$ (D) Tino Polen $^{1}$ (i)
}

Received: 1 August 2020 / Revised: 4 September 2020 / Accepted: 10 September 2020 / Published online: 25 September 2020

(C) The Author(s) 2020

\begin{abstract}
The acetic acid bacterium (AAB) Gluconobacter oxydans incompletely oxidizes a wide variety of carbohydrates and is therefore used industrially for oxidative biotransformations. For $G$. oxydans, no system was available that allows regulatable plasmidbased expression. We found that the L-arabinose-inducible $\mathrm{P}_{B A D}$ promoter and the transcriptional regulator AraC from Escherichia coli MC4100 performed very well in G. oxydans. The respective pBBR1-based plasmids showed very low basal expression of the reporters $\beta$-glucuronidase and mNeonGreen, up to 480 -fold induction with $1 \%$ L-arabinose, and tunability from 0.1 to $1 \%$ L-arabinose. In G. oxydans $621 \mathrm{H}$, L-arabinose was oxidized by the membrane-bound glucose dehydrogenase, which is absent in the multi-deletion strain BP.6. Nevertheless, AraC-P ${ }_{B A D}$ performed similar in both strains in the exponential phase, indicating that a gene knockout is not required for application of AraC- $\mathrm{P}_{B A D}$ in wild-type $G$. oxydans strains. However, the oxidation product arabinonic acid strongly contributed to the acidification of the growth medium in $621 \mathrm{H}$ cultures during the stationary phase, which resulted in drastically decreased reporter activities in $621 \mathrm{H} \mathrm{(pH} \mathrm{3.3)} \mathrm{but} \mathrm{not} \mathrm{in} \mathrm{BP.6} \mathrm{cultures} \mathrm{(pH} \mathrm{4.4).}$ These activities could be strongly increased quickly solely by incubating stationary cells in D-mannitol-free medium adjusted to $\mathrm{pH}$ 6, indicating that the reporters were hardly degraded yet rather became inactive. In a pH-controlled bioreactor, these reporter activities remained high in the stationary phase $\left(\mathrm{pH}\right.$ 6). Finally, we created a multiple cloning vector with $\operatorname{araC}-\mathrm{P}_{B A D}$ based on pBBR1MCS-5. Together, we demonstrated superior functionality and good tunability of an AraC- $\mathrm{P}_{B A D}$ system in G. oxydans that could possibly also be used in other AAB.
\end{abstract}

\section{Key points}

- We found the AraC-P $P_{B A D}$ system from E. coli MC4100 was well tunable in G. oxydans.

- In the absence of AraC or L-arabinose, expression from $P_{B A D}$ was extremely low.

- This araC-P $P_{B A D}$ system could also be fully functional in other acetic acid bacteria.

Keywords AraC $\cdot \mathrm{P}_{B A D}$ promoter $\cdot$ Induction $\cdot \mathrm{mNeonGreen} \cdot \beta$-D-Glucuronidase UidA $\cdot$ Membrane-bound dehydrogenase

Electronic supplementary material The online version of this article (https://doi.org/10.1007/s00253-020-10905-4) contains supplementary material, which is available to authorized users.

Tino Polen

t.polen@fz-juelich.de

Philipp Moritz Fricke

p.fricke@fz-juelich.de

Tobias Link

tobias.link@tum.de

Jochem Gätgens

j.gaetgens@fz-juelich.de
Christiane Sonntag

c.sonntag@fz-juelich.de

Maike Otto

maike.otto@bsse.ethz.ch

Michael Bott

m.bott@ fz-juelich.de

IBG-1: Biotechnology, Institute of Bio- and Geosciences, Forschungszentrum Jülich GmbH, 52425 Jülich, Germany 


\section{Introduction}

Controlled expression of target genes to produce proteins for various purposes in a bacterial cell culture at a defined time point is often beneficial or even required in basic research and in biotechnological applications. For inducible expression, various plasmids have been developed and established in many bacteria including Escherichia coli, Pseudomonas sp., Ralstonia sp., Bacillus sp., Lactoccocus sp., Streptomyces sp., mycobacteria, corynebacteria, halophilic bacteria, and others (reviewed in, for example, Chen 2012; Connell 2001; Dilworth et al. 2018; Evans and Mizrahi 2015; Forstner et al. 2007; Gruber et al. 2015; Parachin et al. 2012; Schnappinger and Ehrt 2014; Terpe 2006; Valero 2012). Prominent classical examples are the well-known LacI-, TetR-, and AraC-dependent systems (as well as optimized or modified versions thereof) for inducible expression by addition of the respective inducer. For acetic acid bacteria (AAB), including the most frequently used and studied genera Acetobacter, Gluconobacter, Gluconacetobacter, Komagataeibacter, and Acidiphilium, a low-cost, tight, and strongly inducible expression system has not been reported yet in the literature to the best of our knowledge. Apparently, for the heterologous systems, leakiness is a major issue responsible for the relatively low induction ratios (induced/non-induced) in AAB. In Komagataeibacter rhaeticus iGEM, the TetR-dependent system from transposon Tn 10 with the inducible promoter $\mathrm{P}_{t e t}$ exhibited approximately only 1.5 -fold induction due to high leakiness in the absence of the inducer anhydrotetracycline (Florea et al. 2016). The native Larabinose-inducible AraC-dependent $\mathrm{P}_{B A D}$ system from E. coli exhibited approximately only 5- to 12 -fold induction in Gluconacetobacter xylinus ATCC 700178 , Gluconacetobacter hansenii ATCC 53582, and Komagataeibacter rhaeticus iGEM due to high basal expression and required a high concentration $(4 \%, w / v)$ of the inducer L-arabinose (Teh et al. 2019). The performance of IPTGinducible $L a c I$-dependent expression has not been reported yet for $\mathrm{AAB}$ according to the literature.

The AAB G. oxydans is industrially used for oxidative biotransformations of carbohydrates to produce, e.g., Lsorbose, a precursor in vitamin $\mathrm{C}$ production, dihydroxyacetone, a substance used for tanning lotions, or 6-amino-Lsorbose, a precursor of the antidiabetic drug miglitol (Ameyama et al. 1981; Gupta et al. 2001; Hekmat et al. 2003; Saito et al. 1997; Tkac et al. 2001; Wang et al. 2016). The beneficial ability of $G$. oxydans is the regio- and stereoselective incomplete oxidation of a variety of substrates (e.g., sugars and sugar alcohols) in the periplasm by membrane-bound dehydrogenases $(\mathrm{mDHs})$ and release of resulting products into the cultivation medium (Mamlouk and Gullo 2013; Mientus et al. 2017; Pappenberger and Hohmann 2014). For the fully functional expression of
$\mathrm{mDHs}$ in $G$. oxydans, the promoters of the alcohol dehydrogenase $\left(\mathrm{P}_{\mathrm{GOX} 1067-68}\right)$ and the inositol dehydrogenase $\left(\mathrm{P}_{\mathrm{GOX} 1857}\right)$ have been used in shuttle vectors (Mientus et al. 2017). While $P_{\text {GOX1857 }}$ is repressed in the presence of glucose (Hölscher et al. 2007), $\mathrm{P}_{\mathrm{GOX} 1067-68}$ showed constitutive activity with good expression (Mientus et al. 2017). Other $G$. oxydans promoters classified as strong, moderate, and weak are the constitutive promoters $\mathrm{P}_{\mathrm{GOX} 0264}, \mathrm{P}_{\mathrm{GOX} 0452}$, and $\mathrm{P}_{\mathrm{GOX} 0384}$ from genes encoding ribosomal proteins (Kallnik et al. 2010). Expression from moderate $P_{\mathrm{GOX} 0452}$ has been used to successfully produce membrane-bound PQQ-dependent glucose dehydrogenase (GOX0265) for purification and characterization (Meyer et al. 2013). Expression from weak $\mathrm{P}_{\mathrm{GOX} 0384}$ has been used to successfully produce the succinate dehydrogenase from Acetobacter pasteurianus in G. oxydans as a first step toward a complete tricarboxylic acid cycle (Kiefler et al. 2015). In earlier work with $G$. oxydans, constitutive $\mathrm{P}_{t u f B}$ from $G$. oxydans and from E. coli as well as $\mathrm{P}_{l a c}$ from $E$. coli have been used (Merfort et al. 2006a, b; Schleyer et al. 2008; Tonouchi et al. 2003; Zhang et al. 2010). Since there is no Lac repressor homolog in G. oxydans, also $\mathrm{P}_{\text {lac }}$ is constitutive in $G$. oxydans. Together, the resulting expression plasmids with all these promoters do not allow for gradually induced expression of target genes at a desired time.

Therefore, to provide for $G$. oxydans a tight and strongly inducible plasmid, we tested AraC- $\mathrm{P}_{B A D}$ from the E. coli $\mathrm{K} 12$ derivative MC4100 in a pBBR1-based vector. The plasmids constructed in this study exhibited very low basal reporter gene expression and L-arabinose-dependent induction ratios up to 480 -fold. GC-TOF-MS analysis confirmed oxidation of the inducer L-arabinose to L-arabinonic acid contributing to the acidification of the growth medium in shake flasks. This additional acidification turned out to be critical for the activity of intracellular reporter proteins in the stationary phase and could be eliminated by $\mathrm{mDH}$ deletion or $\mathrm{pH}-$ controlled conditions.

\section{Materials and methods}

\section{Bacterial strains, plasmids, and culture conditions}

Strains and plasmids used or created in this study are listed in Table 1. G. oxydans strains were routinely cultivated at $30^{\circ} \mathrm{C}$ and $180 \mathrm{rpm}$ in D-mannitol medium containing $4 \%(w / v)$ Dmannitol, $5 \mathrm{~g} \mathrm{~L}^{-1}$ yeast extract, $1 \mathrm{~g} \mathrm{~L}^{-1} \mathrm{KH}_{2} \mathrm{PO}_{4}, 1 \mathrm{~g} \mathrm{~L}^{-1}$ $\left(\mathrm{NH}_{4}\right)_{2} \mathrm{SO}_{4}$, and $2.5 \mathrm{~g} \mathrm{~L}^{-1} \mathrm{MgSO}_{4} \times 7 \mathrm{H}_{2} \mathrm{O}$ and supplemented with $50 \mu \mathrm{g} \mathrm{mL}^{-1}$ cefoxitin. Unless stated otherwise, for shake flask cultivations, $50 \mathrm{~mL}$ of D-mannitol medium in $500 \mathrm{~mL}$ shaking flasks with three baffles was inoculated from overnight starter cultures to an initial optical density at $600 \mathrm{~nm}$ $\left(\mathrm{OD}_{600}\right)$ of 0.3 (UV-1800, Shimadzu). If required for induction tests, $\mathrm{L}$-arabinonic acid was supplemented as $\mathrm{Li}^{+}$salt 
Table 1 Strains and plasmids used or constructed in this study

Relevant characteristics

Reference/source

Strain
E. coli $\mathrm{DH} 5 \alpha$
E. coli $\mathrm{S} 17-1$
G. oxydans $621 \mathrm{H}$
G. oxydans BP.6

Plasmid

pBAD/Myc-His A

pBBR1MCS-2

pBBR1MCS-2-araC- $\mathrm{P}_{B A D}$-uidA

pBBR1MCS-2-araC-P $\mathrm{P}_{B A D}-m N G$

pBBR1MCS-2-P $\mathrm{GOX}_{\mathrm{GO} 64}-m N G$

pBBR1MCS-5

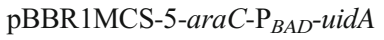

pBBR1MCS-5-araC- $\mathrm{P}_{B A D}-m N G$

pBBR1MCS-5- $\mathrm{P}_{B A D}-m N G$

pBBR1MCS-5-araE-araC-P $\mathrm{P}_{B A D}-m N G$

pBBR1MCS-5-araC- $\mathrm{P}_{B A D}-\mathrm{MCS}$

pBBR1MCS-5-araC-P ${ }_{B A D}$-MCS- $m N G$

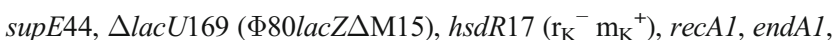
gyrA96, thi-1, relA1

$\triangle r e c A$, endA1, hsdR17, supE44, thi-1, tra ${ }^{+}$

DSM 2343

$621 \mathrm{H}$ derivative carrying $\Delta u p p$ and gene deletions for six $\mathrm{mDHs}$

Vector for dose-dependent expression of recombinant proteins containing a $6 \times$ His tag in E. coli

Derivative of pBBR1MCS; $\mathrm{Km}^{\mathrm{R}}$

Derivative of pBBR1MCS-2 carrying reporter gene uidA controlled by L-arabinose-induced promoter $\mathrm{P}_{B A D}$ and $\operatorname{araC}$ encoding $\mathrm{P}_{B A D}$ regulator AraC

Derivative of pBBR1MCS-2-araC-P $\mathrm{P}_{B A D^{-}}$uidA using reporter gene $m N G$ instead of uidA

Derivative of pBBR1MCS-2 carrying reporter gene $m N G$ controlled by the strong constitutive promoter of GOX0264

Derivative of pBBR1MCS; $\mathrm{Gm}^{\mathrm{R}}$

Derivative of pBBR1MCS-5 carrying reporter gene uidA controlled by L-arabinose-induced promoter $\mathrm{P}_{B A D}$ and $\operatorname{araC}$ encoding $\mathrm{P}_{B A D}$ regulator AraC

Derivative of pBBR1MCS-5-araC- $\mathrm{P}_{B A D}$-uidA using reporter gene $m N G$ instead of uidA

Derivative of pBBR1MCS-5-araC- $\mathrm{P}_{B A D^{-}} m N G$, lacking the regulator gene $\operatorname{araC}$ and carrying the terminator of $g d h M$ (GOX0265) upstream of $\mathrm{P}_{B A D}$

Derivative of pBBR1MCS-5-araC- $\mathrm{P}_{B A D^{-}} m N G$ carrying gene araE encoding L-arabinose transporter AraE

pBBR1MCS-5-based empty vector for AraC-P $\mathrm{P}_{B A D}$-dependent expression of target genes cloned into the MCS provided

Derivative of pBBR1MCS-5-araC-P $\mathrm{P}_{B A D}$-MCS with $m N G$ as reporter gene inserted into the MCS when using the restriction enzymes NdeI and XhoI
Hanahan (1983)

Simon et al. (1983)

DSMZ

Peters et al. (2013)

Invitrogen

Kovach et al. (1995)

This work

This work

This work

Kovach et al. (1995)

This work

This work

This work

This work

This work

This work directly to the medium. The $\mathrm{pH}$ of the supplemented medium was adjusted to $\mathrm{pH} 6$, cold sterile filtered and directly used for cultivation. Cultivations of $G$. oxydans harboring pBBR1MCS-2- or pBBR1MCS-5-based plasmids were supplemented with $50 \mu \mathrm{g} \mathrm{mL}^{-1}$ kanamycin or $10 \mu \mathrm{g} \mathrm{mL}^{-1}$ gentamicin, respectively (Kovach et al. 1995). Escherichia coli strains were routinely cultivated in lysogeny broth (LB) medium at $37^{\circ} \mathrm{C}$ and $160 \mathrm{rpm}$. If appropriate, $50 \mu \mathrm{g} \mathrm{mL}^{-1} \mathrm{kana}-$ mycin or $10 \mu \mathrm{g} \mathrm{mL}^{-1}$ gentamicin was added to the medium. $G$. oxydans was transformed by conjugation using E. coli $\mathrm{S} 17-$ 1 as a donor (Kiefler et al. 2017). All E. coli strains were made competent and transformed by $\mathrm{CaCl}_{2}$ procedure (Hanahan 1983).

\section{Enzymatic determination of L-arabinose concentrations}

L-Arabinose concentrations in the medium of the G. oxydans strains $621 \mathrm{H}$ and BP. 6 were determined using the enzymatic L-arabinose and D-galactose rapid assay kit (Megazyme). All samples were measured in microplates according to the manufacturer's instructions by monitoring NADH formation as increase in absorption at $340 \mathrm{~nm}$ in a multi-well reader (infinite M1000 PRO, Tecan).

\section{DNA microarray analysis}

To analyze short-term gene expression changes in response to a pulse of $1 \%(w / v)$ L-arabinose, the transcriptomes of G. oxydans $621 \mathrm{H}$ cultivated in complex medium with $4 \%$ $(w / v)$ D-mannitol were compared with the control. In the mid-exponential growth phase, $1 \%(w / v)$ L-arabinose was supplemented and the same volume of water in another $621 \mathrm{H}$ culture as a control. After 30 min of cultivation, each cell suspension was harvested by centrifugation $(4500 \times \mathrm{g}, 5 \mathrm{~min}$, $\left.4{ }^{\circ} \mathrm{C}\right)$. The resulting cell pellets were directly frozen in liquid nitrogen and stored at $-80{ }^{\circ} \mathrm{C}$ until RNA preparation. The preparation of RNA, cDNA synthesis, hybridization using Agilent's 4-plex DNA microarray platform, and data analysis were carried out as described (Kranz et al. 2018). 


\section{Recombinant DNA work}

All DNA oligonucleotides used in this study were synthesized by Eurofins MWG and are listed in Table S1. All enzymes for recombinant DNA work were purchased from Thermo Scientific. DNA manipulations by polymerase chain reaction (PCR), restriction, and ligation reactions followed standard protocols (Sambrook et al. 1989). Reporter plasmids were constructed from amplified DNA fragments and the restricted broad-host vectors pBBR1MCS-2 or pBBR1MCS-5 in a onestep isothermal Gibson assembly (Gibson et al. 2009). The terminator sequence BBa_B1002 from the iGEM parts library was placed downstream of the reporter genes. For DNA amplification by PCR, Q5 polymerase was used according to the conditions recommended by the manufacturer (New England Biolabs). All DNA modifications used to obtain designed plasmids were performed with $E$. coli DH5 $\alpha$. Plasmids were isolated from $E$. coli using a QIAprep spin miniprep kit (Qiagen). The plasmid inserts constructed in this work were checked by DNA sequencing (Eurofins MWG).

\section{Construction of plasmids}

Plasmid pBBR1MCS-2-araC- $\mathrm{P}_{B A D}$-uidA was constructed using the primer pairs $\mathrm{PF} 1 / \mathrm{PF} 2$ and $\mathrm{PF} 3 / \mathrm{PF} 4$ to generate a 1253-bp DNA fragment with araC- $\mathrm{P}_{B A D}$ from the commercially available plasmid pBAD/Myc-His A (Invitrogen/ Thermo Fischer) and a 1886-bp DNA fragment with uidA from $E$. coli $\mathrm{K} 12$ genomic DNA and the terminator BBa_B1002 inserted by elongating the 5 -end of PF4. Plasmid pBBR1MCS-2-araC-P ${ }_{B A D^{-}} m N G$ was constructed using the primer pairs $\mathrm{PF} 1 / \mathrm{PF} 5$ and $\mathrm{PF} 6 / \mathrm{PF} 7$ to generate a 1,238 bp DNA fragment with $\operatorname{araC}-\mathrm{P}_{B A D}$ and a $790 \mathrm{bp}$ DNA fragment with $m N G$ and terminator BBa_B1002, respectively. For insertion of the two overlapping DNA fragments into pBBR1MCS-2 by Gibson assembly $\left(50^{\circ} \mathrm{C} ; 1 \mathrm{~h}\right)$, pBBR1MCS-2 was restricted by the endonucleases $\mathrm{SacI}$ and $K p n I$. Elongated 5'-ends in primers PF2/PF3 and PF5/PF6 were used to introduce downstream of $\mathrm{P}_{B A D}$ and $6 \mathrm{bp}$ upstream of the start codon of $m N G$ or uidA, the artificial Shine-Dalgarno sequence AGGAGA (Hentschel et al. 2013). To change the plasmid backbone from pBBR1MCS2 to pBBR1MCS-5, araC-P $\mathrm{P}_{B A D^{-}}$uidA and araC $-\mathrm{P}_{B A D^{-}}-m N G$ were excised and ligated into pBBR1MCS-5 using SacI and Eco81I.

The plasmid pBBR1MCS-5-P $\mathrm{P}_{B A D}-m N G$ was constructed using the primer pair PF8/PF9 to obtain a 1164-bp DNA fragment $\mathrm{P}_{B A D^{-}} m N G$ from pBBR1MCS-5-araC-P $\mathrm{P}_{B A D^{-}} m N G$. The resulting fragment was cloned into pBBR1MCS-5 using BamHI and XhoI. To prevent undesired transcripts initiating from $\mathrm{P}_{B A D}$, the G. oxydans terminator of $g d h M$ (GOX0265) was inserted upstream of $\mathrm{P}_{B A D}$.
Plasmid pBBR1MCS-5-araE-araC- $\mathrm{P}_{B A D}-m N G$ was constructed by insertion of araE into pBBR1MCS-5-araC$\mathrm{P}_{B A D^{-}} m N G$. For that, pBBR1MCS-5-araC- $\mathrm{P}_{B A D^{-}} m N G$ was restricted by the enzymes $A s c I$ and Eco81I and a 1576-bp DNA fragment comprising araE without own promoter, amplified with the primer pair PF10/PF11 from E. coli K12 genomic DNA, was integrated downstream of araC by Gibson assembly. PF10 and PF11 contained elongated 5'-ends to insert the $\mathrm{T} 7$ terminator sequence downstream of $\operatorname{araE}$ and a Shine-Dalgarno sequence upstream of araE between $\operatorname{araE}$ and $\operatorname{araC}$. Thus, $\operatorname{araE}$ and $\operatorname{araC}$ are expected to be expressed as a polycistronic transcript from the $\mathrm{araC}$ promoter.

Plasmid pBBR1MCS-5-araC- $\mathrm{P}_{B A D}$-MCS as an empty vector with a ribosome-binding site, a new $N d e$ I site upstream of the multiple cloning site (MCS) and the IGEM terminator sequence BBa_B1002 was constructed in two steps. In the first step, the DNA fragment araC- $\mathrm{P}_{B A D}$ generated with the primer pair PF12/PF13 was inserted into BshTI/SacI-restricted pBBR1MCS-5 by Gibson assembly keeping the original MCS from pBBR1MCS-5. In the second step, the terminator sequence BBa_B1002 was integrated downstream of the MCS by integration of a DNA fragment amplified with the primer pair PF14/PF15. For the integration of the terminator sequence, the plasmid obtained in step one was restricted with $X h o \mathrm{I}$ and $S p h$ I.

Plasmid pBBR1MCS-5-araC-P $\mathrm{P}_{B A D}$-MCS- $m N G$ was constructed from pBBR1MCS- 5 by integration of the DNA fragments araC-P $\mathrm{P}_{B A D}$ and $m N G$-BBa_B1002 in a Gibson assembly. In the amplification of the DNA fragments, the restriction sites NdeI and XhoI were integrated resulting in the same sequence as it would have been obtained via classical restriction cloning of $m N G$ into pBBR1MCS-5-araC-P ${ }_{B A D}$-MCS using the restriction enzymes $N d e I$ and $X h o I$. The DNA fragments $\operatorname{araC}-\mathrm{P}_{B A D}$ and $m N G$-BBa_B1002 were amplified with the primer pairs PF1/PF16 and PF17/PF18, respectively. For integration, pBBR1MCS-5 was restricted using the restriction enzymes BshTI and KpnI.

\section{Measurements of fluorescence protein and enzyme activity}

For online monitoring of expression induction and relative promoter strengths of promoter-reporter constructs in G. oxydans, the fluorescence protein mNeonGreen (mNG) was used (Shaner et al. 2013). In shake flask experiments, $m N G$ expression in $G$. oxydans was induced by addition of $1 \%(w / v)$ L-arabinose from a $50 \%(w / v)$ stock solution. Reference cultures were supplemented with an equal volume of water. In intervals, growth $\left(\mathrm{OD}_{600}\right)$ and fluorescence emission was monitored by a spectrophotometer (UV-1800, Shimadzu) and a Tecan Reader $\left(\lambda_{\text {ex }} 504 \mathrm{~nm} / \lambda_{\text {em }} 517 \mathrm{~nm}\right.$; gain 60; ex/em bandwidth $5 \mathrm{~nm}$; infinite M1000 PRO, Tecan), respectively. In BioLector cultivations using 48 -well 
Flowerplates ${ }^{\circledR}(\mathrm{m} 2 \mathrm{p}$-labs), batches of $800 \mu \mathrm{L}$ of D-mannitol medium were inoculated from overnight precultures and incubated (1200 rpm; $85 \%$ humidity, $30^{\circ} \mathrm{C}$ ). Over a period of up to $30 \mathrm{~h}$, cell growth and fluorescence was monitored in each well simultaneously by measuring the backscatter $\left(\mathrm{A}_{620 \mathrm{~nm}}\right.$; gain 20) and fluorescence emission ( $\lambda_{\mathrm{ex}} 510 \mathrm{~nm} / \lambda_{\mathrm{em}} 532 \mathrm{~nm}$; gain 60). Typically, mean values and standard deviations of all experiments were derived from at least three biological replicates.

For enzymatic reporter assays, $\beta$-D-glucuronidase (UidA) was used (Kallnik et al. 2010). UidA activity was determined in a Miller assay essentially as described (Miller 1992). Immediately after inoculation of $G$. oxydans shake flask cultures, uidA expression was induced by the addition of $1 \%(\mathrm{w} /$ v) L-arabinose. Non-induced cultures supplemented with an equal volume of water were used as controls. In intervals, $500 \mu \mathrm{L}$ samples were taken to determine $\mathrm{OD}_{600}$ and UidA activity. For permeabilization of the cells, $30 \mu \mathrm{L}$ of the culture broth in appropriate dilutions in assay buffer was incubated in a 96-well plate $\left(20 \mathrm{~min} ; 30^{\circ} \mathrm{C}\right.$ ) with $100 \mu \mathrm{L}$ of prewarmed Z$\operatorname{mix}\left(54.6 \mathrm{mM} \mathrm{Na}_{2} \mathrm{HPO}_{4} \times 7 \mathrm{H}_{2} \mathrm{O}, 36.4 \mathrm{mM} \mathrm{NaH}_{2} \mathrm{PO}_{4} \times \mathrm{H}_{2} \mathrm{O}\right.$, $9.1 \mathrm{mM} \mathrm{KCl}, 0.9 \mathrm{mM} \mathrm{MgSO}_{4}, 45.5 \mathrm{mM}$ DTT, $4.5 \%(v / v)$ chloroform, $0.5 \%(w / v)$ SDS, $\mathrm{pH} 7)$. After the addition of $100 \mu \mathrm{L}$ of prewarmed 4-nitrophenyl- $\beta$-D-glucopyranoside $\left(4 \mathrm{~g} \mathrm{~L}^{-1}\right)$ using a multichannel pipette, $\beta$-D-glucuronidase activity was monitored measuring the absorption of $p$-nitrophenol in intervals of $1 \mathrm{~min}$ at $420 \mathrm{~nm}$ (infinite M1000 PRO, Tecan). From all constructs, at least three biological replicates were measured in triplicates to determine mean values and standard deviations.

\section{Cell flow cytometer analysis}

For single cell analysis of reporter gene expression, the G. oxydans strains $621 \mathrm{H}$ and BP.6 carrying the plasmid

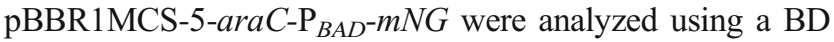
FACSAria II cell sorter (BD Biosciences) equipped with a $70-\mu \mathrm{m}$ nozzle run with a sheath pressure of $70 \mathrm{psi}$. Using the $488 \mathrm{~nm}$ laser beam, the front scatter (FSC) and side scatter (SSC) were recorded as small-angle (axial) and perpendicular scatter, respectively. Combining a 502-nm-long-pass and 530/ $30 \mathrm{~nm}$ band-pass filter, the emitted $\mathrm{mNG}$ fluorescence from the SSC signal was detected. Fluorescence data were acquired using a two-step gating strategy: at first, signals from cell debris and electronic noise were excluded by gating a population in a FSC-H vs. an SSC-H plot. Secondly, to perform singlet discrimination, from the resulting population the FSC$\mathrm{H}$ signal was plotted against FSC-W. The gated singlet population was used for fluorescence acquisition in all experiments. While the total event rate during measurements never exceeded 15,000 events/s, for each sample, the signals of 100,000 events were recorded. For FACS device control and data analysis, FACSDiva 7.0.1 software (BD Biosciences) was used. Gated events $(n=100,000)$ were used for data analysis in FlowJo for Windows 10.4.2 (FlowJo, LLC) and Prism 7.04 (GraphPad Software) to visualize FACS data.

\section{Bioreactor cultivation of G. oxydans}

Bioreactor cultivations were conducted in DASbox ${ }^{\circledR}$ minibioreactors controlled by DASware software (Eppendorf). In 385-mL glass vessels equipped with two 6-bladed Rushtontype impellers, $\mathrm{O}_{2}$ (InPro® 6800 series, Mettler-Toledo), $\mathrm{pH}$ (EasyFerm Plus K8 120, Hamilton), and temperature sensors, 150-mL 4\% (w/v) D-mannitol medium was inoculated to an initial $\mathrm{OD}_{600}$ of $0.3\left(30^{\circ} \mathrm{C}\right)$. The initial gas flow rate was set to $6 \mathrm{sL} \mathrm{h}^{-1}$. Starting agitation frequency was $500 \mathrm{rpm}$. The $\mathrm{pH}$ was maintained at 6 by automatic titration using $\mathrm{H}_{2} \mathrm{SO}_{4}$ or $\mathrm{KOH}$ stocks $(1.5 \mathrm{M})$. Dissolved oxygen tension in the medium was maintained $\geq 30 \%$ by a cascade of first adjusting the agitation speed to a maximum of $1200 \mathrm{rpm}$, then by rising the $\mathrm{O}_{2}$ concentration in the supplied gas up to $80 \%(v / v)$ and eventually by increasing the gas flow rate. In intervals, samples were taken from the culture broth and $\mathrm{OD}_{600}$ as well as fluorescence were determined as described above.

\section{L-Arabinose biotransformation for the analysis of oxidation products}

To identify the reaction products of L-arabinose oxidation by G. oxydans strains, cells were grown in $25 \mathrm{~mL}$ of D-mannitol medium in $500 \mathrm{~mL}$ shake flasks to an $\mathrm{OD}_{600}$ of 1.6, centrifuged $(4000 \times g, 5 \mathrm{~min})$ and washed twice with $1 \mathrm{mM}$ HEPES $(\mathrm{pH} 7$ ). The pellet was resuspended in $25 \mathrm{~mL}$ biotransformation buffer $\left(33.9 \mathrm{~g} \mathrm{~L}^{-1} \mathrm{Na}_{2} \mathrm{HPO}_{4}, 15 \mathrm{~g} \mathrm{~L}^{-1} \mathrm{KH}_{2} \mathrm{PO}_{4}, 5 \mathrm{~g} \mathrm{~L}^{-1}\right.$ $\mathrm{NH}_{4} \mathrm{Cl}, 2.5 \mathrm{~g} \mathrm{~L}^{-1} \mathrm{NaCl}, 0.49 \mathrm{~g} \mathrm{~L}^{-1} \mathrm{MgSO}_{4}, 0.02 \mathrm{~g} \mathrm{~L}^{-1} \mathrm{CaCl}_{2}$ ) supplemented with $1 \%(w / v)$ L-arabinose. The cell suspensions were incubated for $24 \mathrm{~h}$ at $30{ }^{\circ} \mathrm{C}$ on a shaker $(180$ rpm). Afterwards, cells were centrifuged $(4000 \times g, 5 \mathrm{~min})$ and the cell-free supernatant was analyzed using a gas chromatograph (Agilent $6890 \mathrm{~N}$, Agilent Technologies) coupled to a Waters Micromass GCT Premier high-resolution time-offlight mass spectrometer (Waters). Sample derivatization, GC-TOF-MS operation, and peak identification were essentially conducted as described (Paczia et al. 2012). Biotransformation medium without cells was used as reference.

\section{Results}

\section{Growth of G. oxydans $621 \mathrm{H}$ in the presence of L- arabinose}

In the present study, we wanted to test L-arabinose-dependent gene expression in G. oxydans $621 \mathrm{H}$ to provide a regulatable 
expression plasmid for this $\mathrm{AAB}$, similar to AraC-dependent vectors constructed for $E$. coli (Guzman et al. 1995). In such a system, the inducer L-arabinose needs to enter the cell where it binds to the transcriptional regulator AraC (Schleif 2010). In the case of G. oxydans $621 \mathrm{H}$, L-arabinose was reported to be oxidized already in the periplasm by the membrane-bound glucose DH GdhM (GOX0265) (Mientus et al. 2017; Peters et al. 2013). Thus, the presence of $\mathrm{L}$-arabinose could affect the growth of $G$. oxydans $621 \mathrm{H}$ by using it as an energy source through oxidation, thereby inactivating the inducer. The G. oxydans multi-deletion strain BP.6 lacks GdhM and exhibited no L-arabinose-oxidizing activity anymore (Peters et al. 2013). Therefore, we first tested the impact of L-arabinose on growth of the G. oxydans strains $621 \mathrm{H}$ and BP.6 in shake flasks. In complex medium supplemented with $1 \%(w / v)$ Larabinose instead of D-mannitol, growth of G. oxydans $621 \mathrm{H}$ was very poor and $\mathrm{OD}_{600}$ merely doubled within $8 \mathrm{~h}$, while strain BP.6 did not grow at all (Fig. 1a). In medium supplemented with 4\% (w/v) D-mannitol plus 1\% (w/v) L-arabinose, both strains grew very similar $\left(\mu=0.18 \pm 0.01 \mathrm{~h}^{-1}\right.$ for $621 \mathrm{H}$ and $0.17 \pm 0.01 \mathrm{~h}^{-1}$ for BP.6) compared with the control condition with $4 \%(w / v)$ D-mannitol, yet without arabinose ( $\mu=0.18 \pm 0.01 \mathrm{~h}^{-1}$ for $621 \mathrm{H}$ and $0.17 \pm 0.01 \mathrm{~h}^{-1}$ for BP.6). In the stationary phase, both strains reached similar final $\mathrm{OD}_{600}$ values independent of the $\mathrm{L}$-arabinose supplementation $\left(621 \mathrm{H} \mathrm{OD}_{600}\right.$ with D-mannitol $3.84 \pm 0.18$ and with D-mannitol + L-arabinose $3.65 \pm 0.28$; BP. $6 \mathrm{OD}_{600}$ with D-mannitol $3.48 \pm 0.26$ and with D-mannitol + L-arabinose $3.66 \pm 0.08$ ). The concentration of L-arabinose supplemented to the medium did not decrease without cells or with BP.6 cells, while in the $621 \mathrm{H}$ cultures L-arabinose was decreased by approximately $80 \%$ within $24 \mathrm{~h}$ (Fig. 1b). This suggested that L-arabinose or its oxidation product did not impair growth of $G$. oxydans.

\section{L-Arabinose is oxidized to L-arabinonic acid and hardly affected global gene expression}

Based on the measurement of whole cell L-arabinose-oxidation activities of $G$. oxydans $\mathrm{mDH}$ deletion strains and of specifically complemented strains using DCPIP as electron acceptor, the membrane-bound glucose $\mathrm{DH}$ is expected to be responsible for L-arabinose oxidation (Mientus et al. 2017; Peters et al. 2013). Therefore, we tested the G. oxydans strains $621 \mathrm{H}$ and BP.6 for L-arabinose oxidation and analyzed the product(s) by GC-TOF-MS analysis. The multi-deletion strain BP.6 lacks six mDHs including the membrane-bound glucose DH GdhM (GOX0265) and still possesses the cytosolic glucose DH (GOX2015) GdhS (Peters et al. 2013). Cell suspensions of each strain with an $\mathrm{OD}_{600}$ of 1.6 were incubated for $24 \mathrm{~h}$ at $30^{\circ} \mathrm{C}$ and $180 \mathrm{rpm}$ in biotransformation buffer supplemented with $1 \%(w / v)$ L-arabinose. Afterwards, cell-free supernatants were obtained for GC-TOF-MS measurements. Strain $621 \mathrm{H}$ clearly oxidized L-arabinose, and L-arabinonic acid was identified as the product, while strain BP.6 consumed only minor amounts of L-arabinose and formed minor amounts of L-arabinonic acid (Fig. S1). The $621 \mathrm{H}$ sample showed two new peaks at retention times $\left(R_{\mathrm{t}}\right) 13.49$ and $14.74 \mathrm{~min}$. The peak at $R_{\mathrm{t}} 13.49 \mathrm{~min}$ had an $\mathrm{m} / \mathrm{z}$, value of 364 , corresponding to arabinonic acid $\gamma$-1,4-lactone with 3 TMS groups. The peak at $R_{\mathrm{t}} 14.74 \mathrm{~min}$ had an $\mathrm{m} / \mathrm{z}$ value of 511 , corresponding to arabinonic acid with 5 TMS groups and a methyl group split off. According to the comparable arbitrary peak areas, data indicated that GdhM did significantly contribute to L-arabinose oxidation. For strain BP.6, only a very low amount of $\mathrm{L}$-arabinonic acid was found $(\sim 3 \%)$ compared with $621 \mathrm{H}$. Together, this indicated that L-arabinose was indeed mainly oxidized by the membrane-bound glucose $\mathrm{DH}$, while the contribution of the cytosolic glucose DH GdhS or another enzyme remaining in strain BP.6 was negligible.

To check whether the addition of $\mathrm{L}$-arabinose as an inducer possibly affects short-term global gene expression in G. oxydans $621 \mathrm{H}$, transcriptomes were compared using DNA microarrays. Addition of $1 \%(w / v)$ L-arabinose in the mid-exponential growth phase to $621 \mathrm{H}$ cells cultured in complex medium with D-mannitol had only very little effects on the relative mRNA levels within 30 min (Table S2). The highest mRNA level increase (2-fold) was found for GOX0707 encoding the DNA protection during starvation protein Dps followed by six hypothetical proteins (1.6- to 1.9-fold). The strongest mRNA level decrease (0.46-fold) was observed for GOX0536 encoding a hydroxamate-type ferrisiderophore receptor followed by its neighboring genes GOX0532 (0.57-fold) and GOX0531 (0.59-fold) encoding the ExbB and ExbD proteins of the TonB-ExbB-ExbD system as well as GOX0758 (0.56-fold) encoding a porin protein. There is no obvious functional link between these genes and L-arabinose metabolism.

\section{Construction of AraC-dependent L-arabinose-induc- ible expression plasmids}

Based on the tight high-level expression vectors containing the $\mathrm{P}_{B A D}$ promoter developed for E. coli (Guzman et al. 1995), Invitrogen commercialized the AraC- $\mathrm{P}_{B A D}$ system for dose-dependent expression of genes with plasmid pBAD/ Myc-His A useful for expression of potentially toxic or essential genes in E. coli. The araC sequence used in $\mathrm{pBAD} / \mathrm{Myc}-$ His A corresponds to the araC sequence of the widely used MC4100 lineage of $E$. coli $\mathrm{K} 12$ (Casadaban 1976). It differs in nine codons from $a r a C$ of the $E$. coli $\mathrm{K} 12$ reference strain MG1655, which could be of advantage for expression in G. oxydans. Six of the nine different codons cluster in the region of the helix-turn-helix motif responsible for DNA binding at the C terminus of AraC (Brunelle and Schleif 1989). Five of these six codons exhibit much higher usage frequency in G. oxydans when using araC from MC4100 instead of 
Fig. 1 Comparisons of the G. oxydans strains $621 \mathrm{H}$ and BP.6. a Growth $\left(\mathrm{OD}_{600}\right)$ in shake flasks in complex medium with $4 \%(w / v)$ D-mannitol or $1 \%(w / v)$ L-arabinose as well as both $4 \%$ $(w / v)$ D-mannitol plus $1 \%(w / v)$ Larabinose. b Arabinose concentrations in complex medium with $4 \%(w / v)$ Dmannitol plus $1 \%(w / v)$ Larabinose in shake flasks. Data represent mean \pm SD from three biological replicates

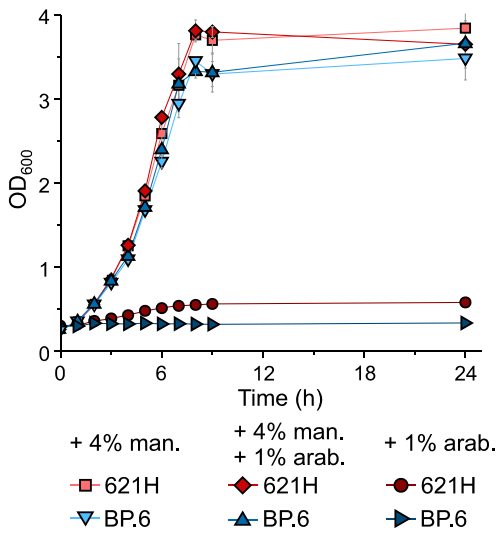

b

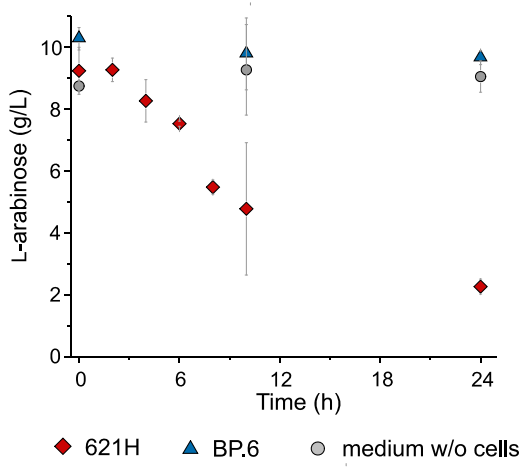

MG1655 (Table S3). Consequently, the AraC-dependent promoter $\mathrm{P}_{B A D}$ flanked by araC from MC4100 and the reporter gene uidA or mNeonGreen was integrated into the multiple cloning site (MCS) as described in "Materials and methods." To enable efficient translation of the reporter, $16 \mathrm{nt}$ containing a proven Shine-Dalgarno sequence functional in G. oxydans was placed between $\mathrm{P}_{B A D}$ and the reporter gene. Furthermore, as a terminator sequence, BBa B1002 was inserted downstream of the reporter genes. We also constructed a reporter plasmid without $\operatorname{araC}$ to test the $\mathrm{AraC}$ dependence of $\mathrm{P}_{B A D}$ in G. oxydans. Another reporter plasmid additionally carried the L-arabinose transporter gene $\operatorname{araE}$ to test the sensitivity of induction towards L-arabinose (Fig. S2).

\section{Performance of the AraC-P $P_{B A D}$ system with enzyme reporter UidA in shake flasks}

With the pBBR1MCS-5-araC-P $\mathrm{P}_{B A D}-u i d A$ plasmid, we tested the basal expression and the induction by L-arabinose using the reporter enzyme $\beta$-D-glucuronidase. Besides $G$. oxydans $621 \mathrm{H}$, which oxidizes L-arabinose by $\mathrm{mDHs}$, we also used the multi-deletion strain BP.6 that is almost unable to oxidize Larabinose to check whether AraC- $\mathrm{P}_{B A D}$ performs better in BP.6 than in $621 \mathrm{H}$. Both strains were grown in shake flasks using D-mannitol medium with and without $1 \%(w / v)$ L-arabinose. For strain $621 \mathrm{H}$, the highest UidA activity was observed at the end of the exponential phase after approximately $9 \mathrm{~h}$ with $12,772 \pm 1604 \mathrm{MU}$ compared with $146 \pm 47 \mathrm{MU}$ in the control cultures without L-arabinose, the latter indicating very low basal expression (Fig. 2a). Strain BP.6 exhibited $11,780 \pm 813 \mathrm{MU}$ after $9 \mathrm{~h}$ in induced cultures compared with $225 \pm 29$ MU in the non-induced controls. Surprisingly, UidA activity in L-arabinose-supplemented $G$. oxydans $621 \mathrm{H}$ was highly reduced after $24 \mathrm{~h}(2,007 \pm 583 \mathrm{MU})$, while UidA activity in BP.6 remained high after $24 \mathrm{~h}(13,209 \pm 715$ MU). When compared with the non-induced cultures, maximal UidA induction ratios of 87 and 59 were calculated for $621 \mathrm{H}$ and BP.6, respectively (Table 2). The lower ratio calculated for BP.6 was primarily due to the somewhat higher basal expression under non-induced condition, while the absolute UidA activity in BP.6 under induced conditions was similar as that in $621 \mathrm{H}$. Generally, the UidA activities in the non-induced cultures did barely surpass the background activity values determined in cell-free control samples. This indicated that the expression plasmid pBBR1MCS-5-araC- $\mathrm{P}_{B A D^{-}}$ uidA showed very low basal expression of $\mathrm{P}_{B A D}$ in the absence of L-arabinose.

\section{Performance of the AraC- $\mathrm{P}_{B A D}$ system with the fluorescence reporter protein $\mathrm{mNeonGreen}$}

For continuous determination of reporter gene expression and its dynamics as well as to verify the strong induction of $\mathrm{P}_{B A D}$ and $\mathrm{AraC}$ dependence in G. oxydans, we also tested the fluorescence reporter protein $\mathrm{mNeonGreen}(\mathrm{mNG})$. In all tests with plasmid pBBR1MCS-5-araC-P $\mathrm{P}_{B A D}-m N G$, the $\mathrm{mNG}$ fluorescence signals in non-induced cultures did barely surpass the background signals of cell-free control samples, suggesting also a very low basal expression of $m N G$. In shake flask cultivations with $1 \%(w / v)$ L-arabinose, the mNG fluorescence in G. oxydans $621 \mathrm{H}$ peaked approximately after $8 \mathrm{~h}$ (Fig. 2b). At the end of the cultivation (24 h), the mNG fluorescence was much lower in strain $621 \mathrm{H}$, while in strain BP.6, the $\mathrm{mNG}$ fluorescence was further increased. The maximal induction ratios based on the absolute or the biomassspecific $\mathrm{mNG}$ fluorescence were calculated to be $289 \pm 75$ or $327 \pm 71$ for strain $621 \mathrm{H}$ and $431 \pm 14$ or $481 \pm 38$ for BP.6, respectively (Table 3). In microscale BioLector cultivations, a similar induction profile was observed (Fig. 2c). The maximal induction ratios based on specific fluorescence were calculated to be $222 \pm 8$ for $621 \mathrm{H}$ and $192 \pm 8$ for BP.6. Again, after entering the stationary phase, the specific $\mathrm{mNG}$ fluorescence steadily decreased and reached zero after about $16 \mathrm{~h}$ in strain $621 \mathrm{H}$, while for strain BP.6, the decrease was much weaker reduced over time and remained high. This was in contrast with the shake flask cultivations, where $\mathrm{mNG}$ 
Table 2 L-Arabinosedependent induction fold changes calculated from UidA activities in $G$ oxydans strains $621 \mathrm{H}$ and BP.6 carrying plasmid pBBR1MCS-5$\operatorname{araC}-\mathrm{P}_{B A D}$-uidA

\begin{tabular}{lcl}
\hline Time (h) & $621 \mathrm{H}$ & BP.6 \\
\hline 2 & $62 \pm 30$ & $16 \pm 5$ \\
4 & $93 \pm 67$ & $35 \pm 7$ \\
7 & $50 \pm 7$ & $34 \pm 12$ \\
9 & $98 \pm 46$ & $53 \pm 3$ \\
24 & $7 \pm 4$ & $52 \pm 3$ \\
\hline
\end{tabular}

Cells were cultivated in shake flasks in Dmannitol medium without and with $1 \%(w /$ v) L-arabinose for induction (Fig. 2a). Data represent mean $\pm \mathrm{SD}$ from three biological replicates fluorescence increased in the stationary phase in strain BP.6 (Fig. 2b). In the late stationary phase (16-24 h), the backscatter values of the $621 \mathrm{H}$ cultures supplemented with $1 \%(w / v) \mathrm{L}-$ arabinose steadily increased further. Measurements of the $\mathrm{OD}_{600}$ in a photometer showed no differences between L-arabinose-supplemented strain $621 \mathrm{H}$ and the non-supplemented $621 \mathrm{H}$ cultures. Additional control measurements with cellfree complex medium adjusted to different $\mathrm{pH}$ values $(\mathrm{pH} 6$, $4.5,4$, and 3.3) revealed differences in backscatters already in cell-free medium due to the differences in $\mathrm{pH}$ that could not be observed in $\mathrm{OD}_{600}$ measurements in a photometer. This suggested that the steady increase of backscatter values in L-arabinose-induced $621 \mathrm{H}$ cultures in the stationary phase resulted from a stronger acidification of the growth medium that cannot be detected by $\mathrm{OD}_{600}$ measurements in a photometer. Taken together, the newly constructed expression plasmids for $G$. oxydans based on the AraC- $\mathrm{P}_{B A D}$ system exhibited very low basal expression of the reporter proteins UidA and $\mathrm{mNG}$ and very strong induction by $1 \%(w / v)$ L-arabinose both in shake flask and in microscale BioLector cultivations (up to 480-fold).

\section{The $P_{B A D}$ promoter is AraC-dependent in G. oxydans and tunable by varying the L-arabinose concentrations}

In E. coli, the regulator $\mathrm{AraC}$ acts as a repressor of $\mathrm{P}_{B A D}$ in the absence of L-arabinose by bending the promoter DNA and stimulates transcription from $\mathrm{P}_{B A D}$ when L-arabinose is present (Schleif 2010; Soisson et al. 1997). To rule out the possibility that in G. oxydans $\mathrm{P}_{B A D}$ is either repressed or activated by a $G$. oxydans protein, the plasmid pBBR1MCS-5- $\mathrm{P}_{B A D^{-}}$ $m N G$ missing the $\operatorname{araC}$ gene was constructed and tested in G. oxydans $621 \mathrm{H}$. In this experiment, no differences in fluorescence were observed between induced and non-induced cells, thus no induction was observed with $1 \%(w / v)$ L-arabinose when AraC was absent (Fig. S3). This result showed that the inducibility of $\mathrm{P}_{B A D}$ in $G$. oxydans is independent of endogenous proteins and indeed specifically dependent on a

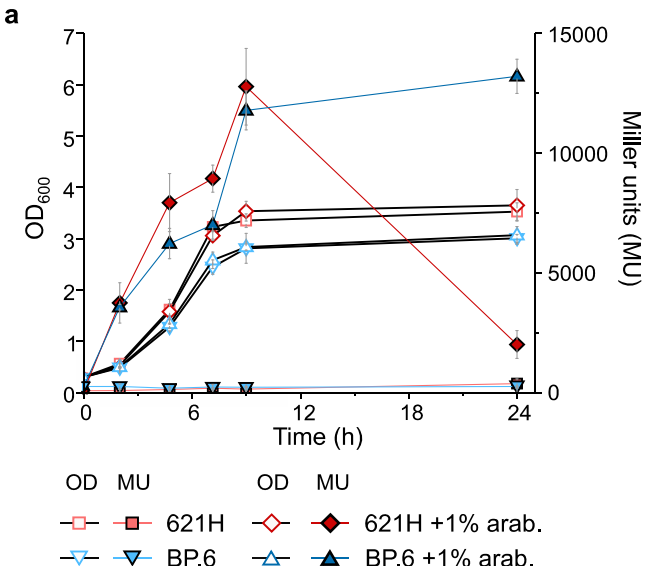

b

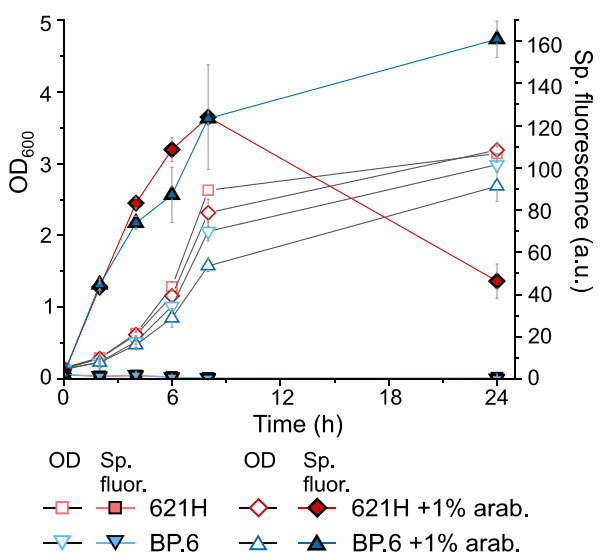

c

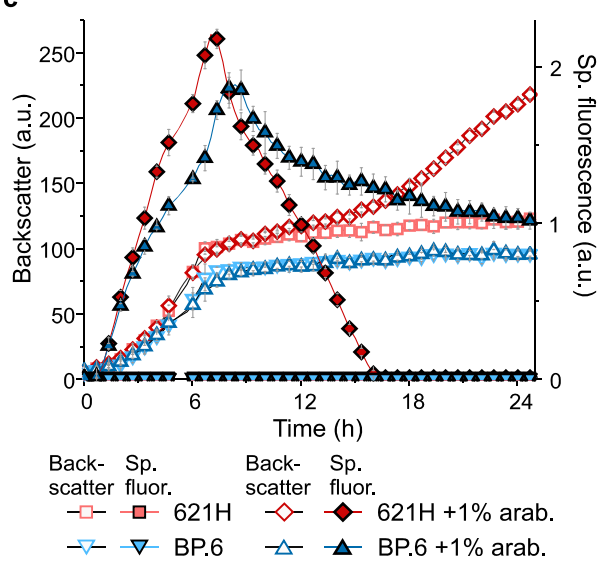

Fig. 2 Comparisons of the G. oxydans strains $621 \mathrm{H}$ and BP.6. a Growth and UidA activity in Miller units (MU) in strains $621 \mathrm{H}$ and BP.6 carrying plasmid pBBR1MCS-5-araC- $\mathrm{P}_{B A D}$-uidA in L-arabinose-induced and noninduced condition in shake flasks. b Growth and specific mNeonGreen (mNG) fluorescence in strains $621 \mathrm{H}$ and BP.6 carrying plasmid pBBR1MCS-5-araC- $\mathrm{P}_{B A D}-m N G$ in L-arabinose-induced and non-induced condition in shake flasks. The $\mathrm{mNG}$ fluorescence was measured in a Tecan reader. The specific fluorescence was calculated from absolute fluorescence per $\mathrm{OD}_{600}$. $\mathbf{c}$ Growth according to backscatter and specific $\mathrm{mNG}$ fluorescence in strains $621 \mathrm{H}$ and BP.6 carrying plasmid pBBR1MCS-5$\operatorname{araC}-\mathrm{P}_{B A D}-m N G$ in L-arabinose-induced and non-induced condition in microscale BioLector cultivations. The specific fluorescence was calculated from absolute fluorescence per backscatter. For induction, always $1 \%(w /$ v) L-arabinose was added to the D-mannitol medium. For all experiments, data represent mean \pm SD from three biological replicates 
heterologous AraC. Furthermore, in the absence of AraC the reporter is almost not expressed from $\mathrm{P}_{B A D}$, thus repression of $\mathrm{P}_{B A D}$ by AraC seemed not to be required in G. oxydans.

The tunability of the AraC- $\mathrm{P}_{B A D}$ system in G. oxydans was tested with a range of $\mathrm{L}$-arabinose concentrations. The $\mathrm{mNG}$ fluorescence gradually increased similarly in strains $621 \mathrm{H}$ and BP.6 with increasing concentrations of L-arabinose (Fig. 3). Compared with $1 \%(w / v)$ L-arabinose, supplementation with $2 \%(w / v)$ L-arabinose did not lead to a significant increase in $\mathrm{mNG}$ fluorescence, indicating saturation of induction at close to $1 \%(w / v)$ inducer. Whereas only a small decrease of the $\mathrm{mNG}$ fluorescence was observed in the stationary phase for the BP. 6 cultures induced with the highest L-arabinose concentrations, $\mathrm{mNG}$ fluorescence for strain $621 \mathrm{H}$ decreased to zero in the stationary phase for the cultures induced with more than $0.5 \%(w / v)$ L-arabinose. In contrast, no decrease was observed for the $621 \mathrm{H}$ cultures with up to $0.25 \% \mathrm{~L}$-arabinose, clearly suggesting a correlation between L-arabinonic acid formation and loss in $\mathrm{mNG}$ fluorescence signals.

Overall, in the exponential growth phase, the performance of the AraC- $\mathrm{P}_{B A D}$ system was very similar in the L-arabinose-oxidizing strain $621 \mathrm{H}$ compared with the multi-deletion strain BP.6. Therefore, we asked whether the oxidation product Larabinonic acid could possibly also act as an inducer on AraC, thereby compensating for the decrease in L-arabinose by its oxidation in $621 \mathrm{H}$ cultures. To test this, we added $1 \%$ $(w / v)$ of L-arabinonic acid to mannitol medium and monitored the mNG fluorescence of strain $621 \mathrm{H}$ with pBBR1MCS-5$\operatorname{araC}-\mathrm{P}_{B A D^{-}} m N G$ in BioLector cultivations. L-Arabinonic acid did not induce the AraC- $\mathrm{P}_{B A D}$ system, since the cultures exhibited a similar background fluorescence as non-induced $621 \mathrm{H}$ cultures without L-arabinose or L-arabinonic acid (Fig. S4).

Table 3 L-Arabinose-dependent induction fold changes calculated from $\mathrm{mNG}$ signals in G. oxydans strains $621 \mathrm{H}$ and BP.6 carrying plasmid pBBR1MCS-5-araC-P $\mathrm{P}_{B A D}-m N G$

\begin{tabular}{|c|c|c|c|c|}
\hline \multirow[t]{2}{*}{ Time (h) } & \multicolumn{2}{|c|}{ abs. fluorescence-fold } & \multicolumn{2}{|c|}{ sp. fluorescence-fold } \\
\hline & $621 \mathrm{H}$ & BP. 6 & $621 \mathrm{H}$ & BP.6 \\
\hline 2 & $38 \pm 4$ & $31 \pm 4$ & $39 \pm 2$ & $32 \pm 3$ \\
\hline 4 & $51 \pm 4$ & $35 \pm 2$ & $53 \pm 3$ & $38 \pm 2$ \\
\hline 6 & $126 \pm 12$ & $73 \pm 9$ & $140 \pm 13$ & $88 \pm 14$ \\
\hline 8 & $289 \pm 75$ & $194 \pm 8$ & $327 \pm 71$ & $254 \pm 16$ \\
\hline 24 & $128 \pm 61$ & $431 \pm 14$ & $125 \pm 58$ & $481 \pm 38$ \\
\hline 30 & $45 \pm 15$ & $327 \pm 20$ & $48 \pm 16$ & $392 \pm 28$ \\
\hline
\end{tabular}

Cells were cultivated in shake flasks in D-mannitol medium with and without $1 \%(w / v)$ L-arabinose for induction (Fig. 2b). Fold changes (1\% L-arabinose vs. no inducer) were calculated from absolute $\mathrm{mNG}$ fluorescence signals (abs.) and from backscatter-related biomass-specific $\mathrm{mNG}$ fluorescence signals (sp.). Data represent mean \pm SD from three biological replicates
The experiments described above showed that L-arabinose is able to activate $\mathrm{AraC}$ in $G$. oxydans, yet it is unknown how L-arabinose enters the $G$. oxydans cytoplasm. Knowledge on sugar transport systems in G. oxydans is scarce in general and no data are available for L-arabinose to our knowledge. The E. coli protein AraE is a low-affinity high-capacity L-arabinose transporter (Khlebnikov et al. 2001). To facilitate L-arabinose uptake by $G$. oxydans and thereby possibly improving the sensitivity of the L-arabinose-inducible system, plasmid pBBR1MCS-5-araE-araC-P $\mathrm{P}_{B A D^{-}} m N G$ was constructed containing araE including a Shine-Dalgarno sequence directly downstream of $\operatorname{araC}$. This should enable co-transcription of araC and araE from $\mathrm{P}_{a r a C}$. When analyzing strain $621 \mathrm{H}$ carrying plasmid pBBR1MCS-5-araE-araC-P $\mathrm{P}_{B A D}-m N G$ with 0.1 and $0.5 \%(w / v)$ L-arabinose, however, the specific fluorescence was 40 to $60 \%$ lower compared with strain $621 \mathrm{H}$ carrying the plasmid without araE (Fig. S5). Thus, no increase in sensitivity towards the inducer was observed with pBBR1MCS-5-araE-araC-P ${ }_{B A D}-m N G$ under the conditions tested.

\section{Acidification of the growth medium is responsible for the decrease in reporter activities}

In the experiments described above, both UidA activity and $\mathrm{mNG}$ fluorescence strongly decreased in the stationary phase of the $621 \mathrm{H}$ cultures induced with $1 \%(w / v)$ L-arabinose but not in the BP. 6 cultures. The decrease correlated with the Larabinose concentration and was absent at concentrations up to $0.25 \%(w / v)$. This clearly indicated that oxidation of L-arabinose affected the dynamics of the reporter activities. According to previous data and our GC-TOF-MS results, strain $621 \mathrm{H}$ oxidizes L-arabinose to L-arabinonic acid by the membrane-bound glucose DH, which is absent in strain BP.6 (Mientus et al. 2017). With a $\mathrm{p} K_{\mathrm{a}}$ of 3.39 (https://hmdb.ca/ metabolites/HMDB0000539), formation of L-arabinonic acid caused an additional acidification of the growth medium. The $\mathrm{pH}$ values of the D-mannitol media of strains $621 \mathrm{H}$ and BP.6 supplemented with $1 \%(w / v)$ L-arabinose decreased from initially pH 6.0 to $3.3 \pm 0.1$ and $4.4 \pm 0.1$, respectively, after $24 \mathrm{~h}$. In contrast, the $\mathrm{pH}$ values of the non-induced cultures were $4.7 \pm 0.1$ and $4.6 \pm 0.1$ for $621 \mathrm{H}$ and BP.6, respectively, after $24 \mathrm{~h}$. These data confirm that L-arabinose oxidation to Larabinonic acid by strain $621 \mathrm{H}$ leads to a stronger acidification of the medium.

Bacteria typically exhibit energy-dependent mechanisms for cytoplasmic $\mathrm{pH}$ homeostasis in order to survive during exposure to acidic or alkaline conditions. The observed decreases in $\mathrm{mNG}$ fluorescence suggested that due to the formation of L-arabinonic acid, the cytoplasmic $\mathrm{pH}$ in strain $621 \mathrm{H}$ increasingly acidified in the stationary phase when cells starved for energy. Recently, it was shown for the mNG protein that a shift from $\mathrm{pH} 6$ to 4 is sufficient to reduce the $\mathrm{mNG}$ 
Fig. 3 L-Arabinose-dependent modulation of expression in the G. oxydans strains $621 \mathrm{H}$ (a) and BP.6 (b) carrying plasmid pBBR1MCS-5-araC-P $\mathrm{P}_{B A D}-m N G$ in microscale BioLector cultivations. Reporter gene $\mathrm{mNG}$ expression was induced with increasing concentrations of Larabinose from 0.03 to $2 \%(w / v)$ as indicated. Data represent mean \pm SD from three biological replicates a

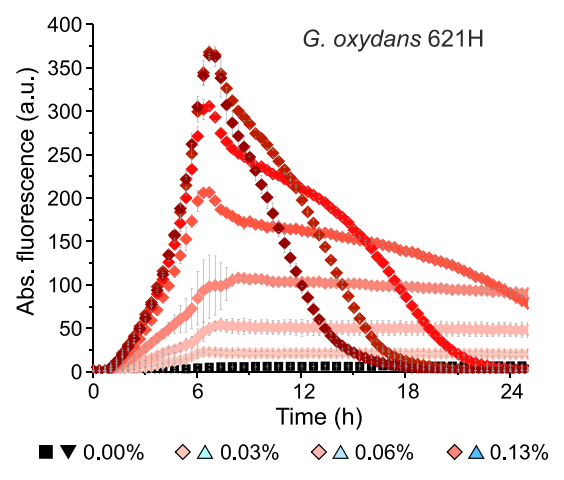

b

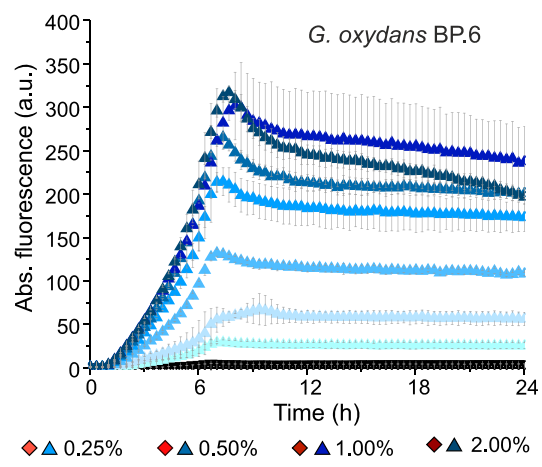

fluorescence by approximately $75 \%$ (Steiert et al. 2018). As described above, the $\mathrm{pH}$ values of induced $621 \mathrm{H}$ cultures after $24 \mathrm{~h}$ were even lower than $\mathrm{pH} 4$. Consequently, we tested whether fresh D-mannitol-free and L-arabinose-free medium adjusted to different $\mathrm{pH}$ values could restore the $\mathrm{mNG}$ fluorescence of stationary phase $621 \mathrm{H}$ cells cultivated with $1 \%(w /$ v) L-arabinose. For this test, we used plasmid pBBR1MCS-2$\mathrm{P}_{\mathrm{GOX} 0264}-m N G$ in order to constitutively express $m N G$ from the strong promoter of GOX0264. As expected, when cultivated with L-arabinose the $\mathrm{mNG}$ fluorescence was clearly decreased in the stationary phase, while without L-arabinose the mNG fluorescence remained high (Fig. S6a). Incubation of the cells grown with L-arabinose for $1 \mathrm{~h}$ in fresh medium adjusted to $\mathrm{pH} 3.5,4.9$, and 6.2 gradually recovered the $\mathrm{mNG}$ fluorescence (Fig. S6b). This result indicated that the decrease in $\mathrm{mNG}$ fluorescence in $621 \mathrm{H}$ cells was hardly due to degradation of the $\mathrm{mNG}$ protein in the stationary phase. Rather, the strong acidification of the growth medium by Larabinonic acid formation in $621 \mathrm{H}$ cultures affected the cytoplasmic $\mathrm{pH}$ during the stationary phase which in turn was responsible for the decrease in $\mathrm{mNG}$ fluorescence.
Furthermore, for G. oxydans $621 \mathrm{H}$ carrying pBBR1MCS-5araC- $\mathrm{P}_{B A D}$-uidA grown with $1 \%(w / v)$ L-arabinose, the loss of UidA activity in the stationary phase $(24 \mathrm{~h})$ was also restored partly when cells were transferred for $1 \mathrm{~h}$ into fresh medium adjusted to $\mathrm{pH} 6$ (Fig. S6c, d).

To analyze the induction of the $\mathrm{AraC}-\mathrm{P}_{B A D}$ system in $G$. oxydans and the $\mathrm{pH}$-dependent decrease and recovery in $\mathrm{mNG}$ fluorescence on the single cell level, flow cytometer analysis was applied. For strain $621 \mathrm{H}, 8 \mathrm{~h}$ after induction, $91 \%$ of all cells exhibited high fluorescence signals (approximately 40,000 a.u.) within the chosen gate, indicating a high population homogeneity close to the end of the exponential growth phase (Fig. 4a). $26 \mathrm{~h}$ after induction, when the $\mathrm{pH}$ of the medium was $3.3 \pm 0.1$, the overall fluorescence was diminished and two distinct populations at approximately 10,000 a.u. and approximately 600 a.u. emerged. Transferring the $621 \mathrm{H}$ cells into D-mannitol-free and L-arabinose-free medium adjusted to $\mathrm{pH} 6$ resulted in a recovery of the $\mathrm{mNG}$ fluorescence in a single population with $83 \%$ exhibiting a fluorescence signal of approximately 30,000 a.u.. For G. oxydans BP.6, also a strong induction with a high

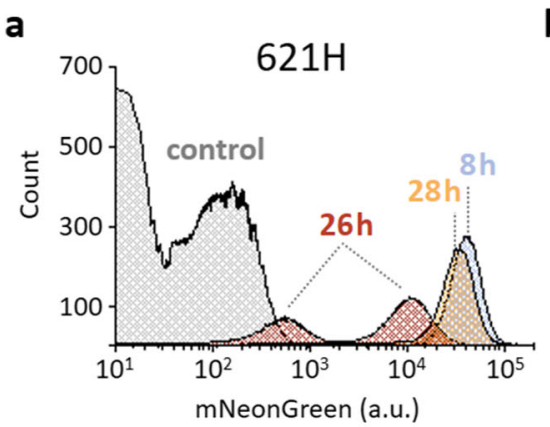

b

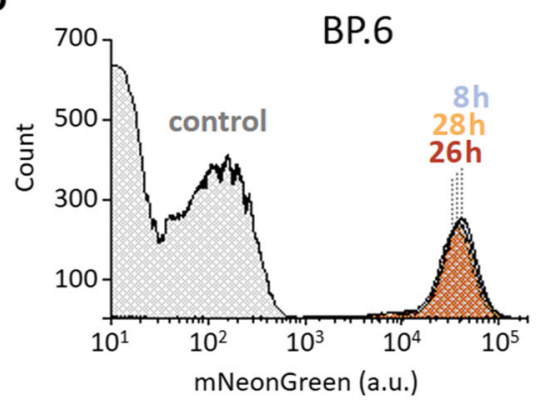

\section{$\square$ 8h $\square$ 26h $\square$ 28h (after $26 \mathrm{~h}$ for $2 \mathrm{~h}$ in pH 6) \\ $\square$ control: $621 \mathrm{H}$ or BP.6 without plasmid}

Fig. 4 FACS analysis of the G. oxydans strains $621 \mathrm{H}$ (a) and BP.6 (b) carrying plasmid pBBR1MCS-5-araC- $\mathrm{P}_{B A D}-m N G$. Cells were grown in shake flasks with D-mannitol medium and induced with $1 \%(w / v) \mathrm{L}$ arabinose. FACS analysis was performed 8 and $26 \mathrm{~h}$ after induction. After $26 \mathrm{~h}$, cells were transferred into fresh L-arabinose- and D- mannitol-free medium adjusted to $\mathrm{pH} 6$ followed by incubation on a rotary shaker for $2 \mathrm{~h}$. As a control, $621 \mathrm{H}$ or BP. 6 cells without plasmids also grown in D-mannitol medium with $1 \%(w / v)$ L-arabinose were used. Total counts per sample represent 100,000 events and only appears to be different due to the logarithmic scale on the $x$-axis 
homogeneity and a fluorescence of about 40,000 a.u. was observed after $8 \mathrm{~h}$. These signals were hardly decreased in the stationary phase after $26 \mathrm{~h}(\mathrm{pH} 4.4 \pm 0.1)$ and were not affected by the transfer into fresh medium adjusted to $\mathrm{pH} 6$ (Fig. 4b). These single cell results are in line with the assumption that additional acidification of the growth medium causes a stronger intracellular acidification in the stationary phase. Furthermore, the single cell data showed that the AraC- $\mathrm{P}_{B A D}$ system enabled a highly uniform induction response in the cells.

\section{UidA activity and $\mathrm{mNG}$ fluorescence are stable in $\mathrm{pH}$ - controlled bioreactor cultivations}

In the following, $\mathrm{pH}$-controlled bioreactor cultivations were carried out to circumvent effects due to acidification of the medium when assaying the performance of the L-arabinoseinducible AraC-P $\mathrm{P}_{B A D}$-system in G. oxydans. Therefore, G. oxydans strains $621 \mathrm{H}$ and BP.6 carrying pBBR1MCS-5-

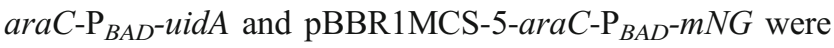
grown in DASbox ${ }^{\circledR}$ mini bioreactors under controlled conditions at $\mathrm{pH} 6$ and dissolved oxygen concentrations above $30 \%$. Sufficient oxygen levels are crucial for maturation of the chromophore (Shaner et al. 2013). After the 24-h fermentation in D-mannitol medium with $1 \%(w / v)$ L-arabinose, the total volume of potassium hydroxide solution consumed to maintain $\mathrm{pH} 6$ in the $621 \mathrm{H}$ cultures $(11.2 \pm 0.7 \mathrm{~mL})$ was much higher compared with the BP. 6 cultures $(6.0 \pm 1.0 \mathrm{~mL})$, which is in line with the L-arabinose oxidation by strain $621 \mathrm{H}$ yielding $\mathrm{L}$-arabinonic acid. As expected, when maintaining a constant $\mathrm{pH}$ of 6 throughout the cultivation, neither the $\mathrm{mNG}$ fluorescence nor the UidA activity decreased in the stationary phase in $621 \mathrm{H}$ cells oxidizing L-arabinose (Fig. 5).

\section{Providing an AraC-P ${ }_{B A D}$-dependent plasmid with a multiple cloning site as empty vector}

Albeit an AraC- $\mathrm{P}_{B A D}$-dependent expression plasmid with genes of interest could be easily obtained by Gibson assembly in an all-in-one fragment mixture cloning, we wanted to provide an AraC-P $\mathrm{P}_{B A D}$-dependent plasmid for G. oxydans with a multiple cloning site as an empty vector for classical restriction enzyme-based cloning attempts to insert genes of interest. Therefore, we assembled ara $C-\mathrm{P}_{B A D}$ with the multiple cloning site from pBBR1MCS-5 and the terminator sequence BBa_B1002 from the iGEM parts library in plasmid pBBR1MCS-5 to obtain plasmid pBBR1MCS-5-araC$\mathrm{P}_{B A D}$-MCS as an empty vector (Fig. 6). In this plasmid, the ribosome binding site AGGAGA was included upstream of the NdeI site newly created upstream of the original MCS by exchanging a single $\mathrm{G}$ to a $\mathrm{C}$. To check the functionality and inducibility of AraC- $\mathrm{P}_{B A D}$ in this empty vector as a multiple cloning reference plasmid, we created the reporter plasmid
pBBR1MCS-5-araC-P ${ }_{B A D}$-MCS- $m N G$ by Gibson assembly resulting in the same sequence as it would have been obtained via classical restriction cloning of $m N G$ using the restriction enzymes NdeI and XhoI. When the resulting plasmid pBBR1MCS-5-araC-P ${ }_{B A D}$-MCS- $m N G$ was tested in strain $621 \mathrm{H}$, again strong induction in the presence of $\mathrm{L}$-arabinose was observed and the basal expression in the absence of $\mathrm{L}$ arabinose was again very low (Fig. S7). However, for unknown reasons the specific $\mathrm{mNG}$ fluorescence reached only approximately $40 \%$ of the maximum observed with the test plasmid always used before and not having the multiple cloning site or remaining parts thereof. Nevertheless, this demonstrated that plasmid pBBR1MCS-5-araC-P $\mathrm{P}_{B A D}$-MCS was also functional and could serve as a multiple cloning vector to insert fragments containing genes of interest and if required own ribosome binding sites.

\section{Discussion}

For the AAB G. oxydans, no expression plasmid was available that shows very low background expression and allows strong and tunable target gene expression. In this study, we found that the AraC- $\mathrm{P}_{B A D}$ system derived from E. coli $\mathrm{K} 12$ MC4100 performed very well in G. oxydans with the pBBR1 plasmid backbone. It exhibited very low basal reporter gene expression, induction ratios up to 480 -fold, and gradually increased expression in an L-arabinose concentration-dependent manner. Typically, the regulatable expression plasmids tested in $\mathrm{AAB}$ species and reported so far suffered from very leaky expression in the absence of the respective inducer, resulting in very low induction ratios for the promoters $\mathrm{P}_{B A D}, \mathrm{P}_{T e t}$ or $\mathrm{P}_{L u x}$, while the overall expression was strong according to the reporter activities (Florea et al. 2016; Teh et al. 2019). Among these three promoters, the best induction ratios were only 5 - to 12-fold for the L-arabinose-inducible AraC- $\mathrm{P}_{B A D}$ system from E. coli when used in G. xylinus 700178, G. hansenii 53582, or K. rhaeticus iGEM (Teh et al. 2019). The reason for the leakiness in $\mathrm{AAB}$ reported for the repressor-regulated promoters is not clear. It seems the binding of the repressors to their target DNA sequences is not strong enough in the cytoplasm of $\mathrm{AAB}$ or there is not enough repressor protein. However, in the case of AraC the mechanism of transcriptional gene regulation is different compared with those of the pure repressor proteins TetR, LuxR, and LacI, which just dissociate from their operators when their respective inducer is bound to the protein. In E. coli, AraC does not only repress $\mathrm{P}_{B A D}$ by looping the DNA when bound to specific target sequences in the absence of L-arabinose but also is essential for activation of $\mathrm{P}_{B A D}$ in the presence of $\mathrm{L}$-arabinose via a modified binding to target sequences, causing unlooping of the promoter DNA and stimulation of both the binding of RNA polymerase and the transition from the closed to the open promoter complex 
Fig. 5 L-Arabinose-inducible reporter gene expression in DASbox fermentations in $\mathrm{pH}-$ controlled conditions ( $\mathrm{pH}$ 6). Both, $\mathrm{mNG}$ and UidA activity remained high in G. oxydans $621 \mathrm{H}$ carrying plasmid pBBR1MCS-5-araC-P $\mathrm{P}_{B A D}-m N G$ (a) or pBBR1MCS-5-araC-P $\mathrm{BAD}^{-}$ uidA (b) $24 \mathrm{~h}$ after induction with $1 \%(w / v)$ L-arabinose when $\mathrm{pH} 6$ was maintained

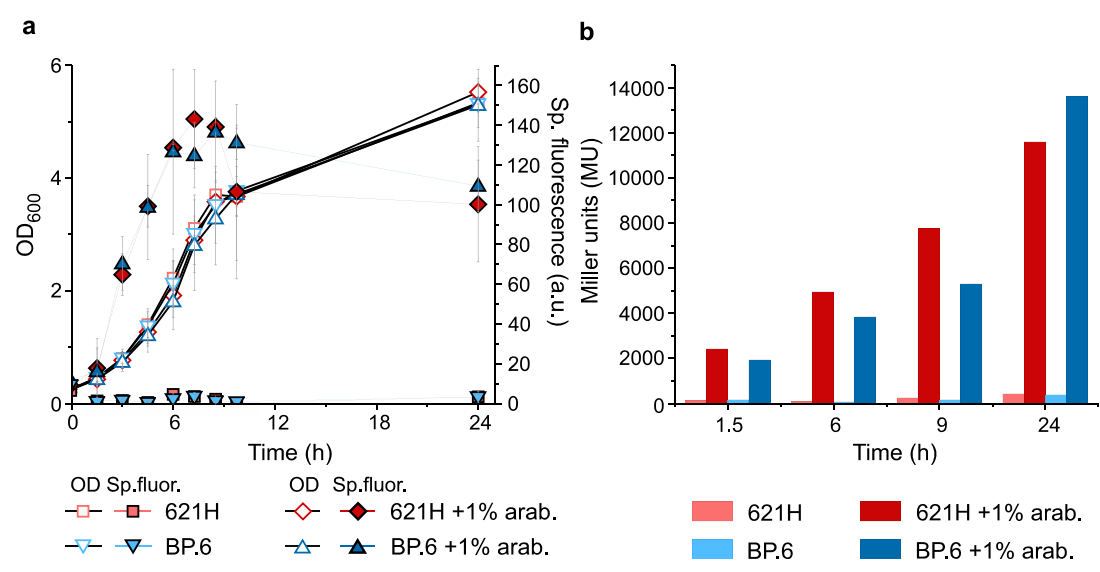

(Schleif 2010; Soisson et al. 1997). Additionally, in E. coli, the cAMP receptor protein (CRP) also plays an important role in the induction of $\mathrm{P}_{B A D}$ by stimulating the opening of the DNA loop and either the binding of the RNA polymerase or the transition to the open complex (Schleif 2010). In the genome of G. oxydans, there is only a single protein (GOX0974/ GOX_RS06010) predicted to belong to the CRP/FNR superfamily of transcriptional regulators (Korner et al. 2003; Kranz et al. 2017; Prust et al. 2005). According to our data, this protein is a member of the FNR family and not a cAMPbinding protein of the CRP family (unpublished). Therefore, CRP appears to be absent in G. oxydans. Furthermore, with plasmid pBBR1MCS-5- $\mathrm{P}_{B A D^{-}} m N G$ missing the araC gene, we confirmed that the induction by L-arabinose specifically depended on $\mathrm{AraC}$ and not on an endogenous G. oxydans protein. The absence of AraC and therefore the missing repression of $\mathrm{P}_{B A D}$ was not sufficient to allow transcription from $\mathrm{P}_{B A D}$ in G. oxydans. A CRP likely absent in G. oxydans could be the reason. This is important in view of leakiness, yet we cannot rule out that in the absence of $\mathrm{AraC}_{B A D}$ is somehow repressed by a $G$. oxydans protein that is displaced from $\mathrm{P}_{B A D}$ when AraC is present. Nevertheless, the activation indicated that in G. oxydans, AraC was functional and required as a transcriptional activator of $\mathrm{P}_{B A D}$, thus heterologous AraC bound to the respective promoter DNA in the cytoplasm and interacted with the RNA polymerase of $G$. oxydans, yet AraC was not required to repress $\mathrm{P}_{B A D}$. Therefore, using transcriptional activation instead of derepression and considering CRP may circumvent the high leakiness of the classical repressorbased expression plasmids in AAB. However, the reason why AraC-P $\mathrm{P}_{B A D}$ from E. coli did not perform well in G. xylinus 700178 , G. hansenii 53582, or $K$. rhaeticus iGEM remains unclear (Teh et al. 2019). We used the araC- $\mathrm{P}_{B A D}$ sequence from $E$. coli $\mathrm{K} 12 \mathrm{MC} 4100$ that exhibits much better codon usage frequencies in G. oxydans for five rare E. coli K12 MG1655 codons located in the C-terminal helix-turn-helix region of AraC responsible for DNA binding. The effects of the different araC codon usage frequencies from MC4100 vs. a

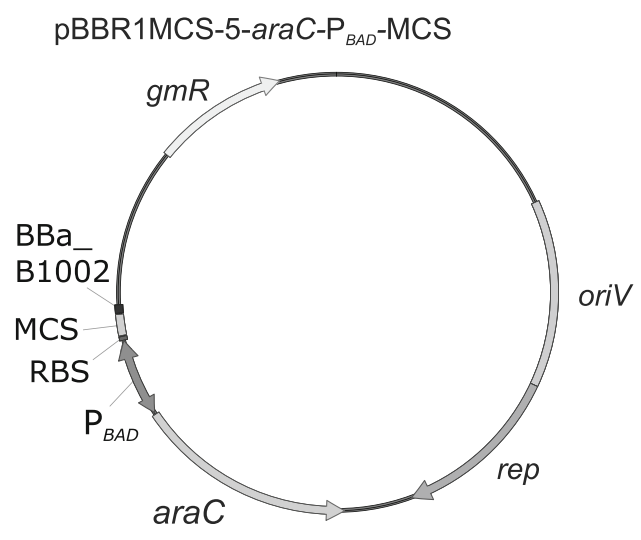

b

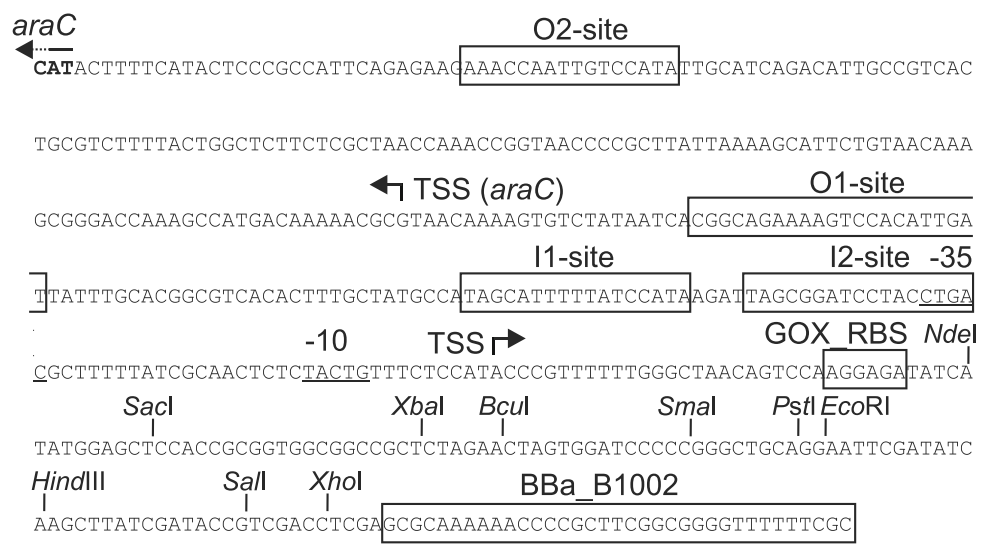

Fig. 6 Scheme of the pBBR1MCS-5-based araC-P $\mathrm{P}_{B A D}$ plasmid with a multiple cloning site (a) and sequence information details (b). The ribosome-binding site AGGAGA (GOX_RBS) is included and usable when the insert cloning is carried out on the 5 '-end by NdeI; otherwise, another RBS needs to be included in the insert upstream of the gene of interest. The iGEM terminator sequence of BBa_B1002 is located downstream of the multiple cloning site (MCS) 
MG1655 in AAB are unknown. Furthermore, differences in the constructed plasmids such as terminators used and the orientations of plasmid-based reporter and resistance genes to each other, as well as further little sequence-specific differences may affect the formation or stability of their transcripts and the resulting translation, thereby affecting the overall performance of the AraC- $\mathrm{P}_{B A D}$ systems in $\mathrm{AAB}$. This can already be seen in the result that even in $G$. oxydans with plasmid pBBR1MCS-5-araC-P ${ }_{B A D}$-MCS- $m N G$, which was very similar to the extremely well-performing plasmid pBBR1MCS-5$\operatorname{araC}-\mathrm{P}_{B A D}-m N G$, only approximately $40 \%$ of the maximal specific $\mathrm{mNG}$ fluorescence was found. This indicated that already the single $\mathrm{G}$ to $\mathrm{C}$ exchange between the RBS and the ATG start codon to create an NdeI site or the short remaining MCS sequence from the XhoI site (CTCGAG) after the stop codon directly upstream of the terminator sequence and overlapping with it by the last $\mathrm{G}$, or even both, somehow negatively affected the resulting $m N G$ transcript or its translation more drastically than one would expect. Further studies are required to analyze these sequence effects in $\mathrm{AAB}$ in more detail.

For induction of the AraC- $\mathrm{P}_{B A D}$ system in E. coli, typically a concentration in the range from 0.001 to $0.2 \%$ of $\mathrm{L}$-arabinose is sufficient (Guzman et al. 1995; Narayanan et al. 2006). In this study with $G$. oxydans and plasmid pBBR1MCS-5-araC$\mathrm{P}_{B A D^{-}} m N G$, a range of approximately 0.1 to $1 \%$ of $\mathrm{L}$-arabinose was required for minimal and maximal induction. This range is much higher compared with $E$. coli and reflects an altered inducer responsiveness of the $\mathrm{AraC}-\mathrm{P}_{B A D}$ system in G. oxydans. The GC-TOF-MS analysis demonstrated that Larabinose was oxidized by the membrane-bound glucose $\mathrm{DH}$ in strain $621 \mathrm{H}$. Nevertheless, in the multi-deletion strain BP.6 almost completely unable to oxidize L-arabinose, the L-arabinose responsiveness of the AraC- $\mathrm{P}_{B A D}$ system was similar as that of strain $621 \mathrm{H}$. Thus, oxidation and the resulting decrease of $\mathrm{L}$-arabinose did not reduce the responsiveness of the AraC$\mathrm{P}_{B A D}$ system, although the oxidation product L-arabinonic acid did not act as an inducer on AraC. Therefore, usage of the AraC- $\mathrm{P}_{B A D}$ system in G. oxydans is not limited to strains that are unable to oxidize L-arabinose.

The lowered responsiveness of the AraC- $\mathrm{P}_{B A D}$ system in $G$. oxydans to L-arabinose might be caused by a very low uptake of the sugar into the cell. Attempts to improve uptake by expression of the $E$. coli araE gene encoding a secondary transporter for $\mathrm{L}$-arabinose did not increase the responsiveness and even had a negative effect on the expression of the reporter gene $m N G$ in our case. The reason for this result is unclear. It might be related to the co-expression of araE with araC resulting in a longer transcript than araE or araC mRNA alone. The longer transcript could be less stable or could form secondary structures that negatively affect the translation process, both yielding less AraC activator protein. Additional experiments with separate expression of araE from a constitutive promotor independent of araC $-\mathrm{P}_{B A D}$ or alternative arabinose transporter genes are necessary to elucidate the potential to improve the responsiveness of the araC $-\mathrm{P}_{B A D}$ system in G. oxydans (Khlebnikov et al. 2001). An endogenous L-arabinose transporter is not known in G. oxydans (Prust et al. 2005). A BLAST search with the E. coli AraE protein sequence in the $G$. oxydans proteome revealed three proteins with 46 to $56 \%$ sequence identity. GOX0808 (56\% identity) is annotated as a galactose-proton symporter, GOX0649 (51\% identity) as a sugar-proton symporter, and GOX1971 (46\% identity) also as a galactose-proton symporter. One or several of these transporters might be promiscuous and poorly take up L-arabinose as a side reaction. No data are available on the substrates, properties, and physiological functions of these transporters.

With respect to the question if $\mathrm{L}$-arabinose can be degraded within $G$. oxydans cells, our results in which this sugar was used in complex medium as sole supplement and as cosubstrate with D-mannitol argue against this possibility. With L-arabinose alone strain $621 \mathrm{H}$ showed maximally one doubling while strain BP.6 showed no growth at all. This suggested that oxidation of L-arabinose somewhat contributed to generate energy in $621 \mathrm{H}$ for growth, yet not in BP. 6 unable to oxidize L-arabinose. In E. coli and other bacteria, L-arabinose is catabolized via an initial isomerization to L-ribulose catalyzed by AraA, followed by phosphorylation to L-ribulose 5phosphate catalyzed by AraB, and epimerization to D-xylulose 5-phosphate catalyzed by AraD (Englesberg 1961; Englesberg et al. 1962). In G. oxydans, homologs of AraA and AraD are absent and only a protein annotated as ribulokinase (GOX2186) showing 26\% sequence identity to E. coli AraB was found. Therefore, L-arabinose taken up by G. oxydans is probably not converted to an intermediate like D-xylulose 5-phosphate that could be catabolized in the pentose phosphate pathway.

The oxidation of L-arabinose by $G$. oxydans $621 \mathrm{H}$ did not affect the inducibility of $\mathrm{P}_{B A D}$, yet as a side effect the growth medium was much more acidified due to the formation of $\mathrm{L}-$ arabinonic acid. Therefore, when expressing target genes encoding $\mathrm{pH}$-sensitive proteins in batch cultures without $\mathrm{pH}$ control, the use of a G. oxydans strain like BP. 6 that lacks the ability to oxidize L-arabinose is beneficial to preserve the activity of the target protein in the stationary phase. In the case of strain $621 \mathrm{H}$, additional acidification of the medium due to Larabinonic acid formation resulted in a severe loss of UidA activity and $\mathrm{mNG}$ fluorescence in the stationary phase. Both, UidA activity and mNG fluorescence could be partly or almost fully recovered by solely transferring the cells into fresh medium adjusted to $\mathrm{pH} 6$, indicating that at least the $\mathrm{mNG}$ protein was hardly degraded. The activity of the $\beta$-D-glucuronidase UidA is reduced by half when the $\mathrm{pH}$ is lowered to 4.3 compared with the activity in the optimal range of $\mathrm{pH} 5.0$ to 7.5 (Jefferson et al. 1986). For mNG, it was shown that 
between $\mathrm{pH} 5$ and 6 , three different protonated forms of the chromophore are present. When lowering the $\mathrm{pH}$ from 6 to 4 , the acidic form becomes predominant, which decreases the fluorescence intensity by half and at $\mathrm{pH} 3$ the $\mathrm{mNG}$ fluorescence is completely lost (Steiert et al. 2018). Our flow cytometry analysis revealed the occurrence of two subpopulations of $621 \mathrm{H}$ cells with reduced $\mathrm{mNG}$ fluorescence $26 \mathrm{~h}$ after induction in medium with a $\mathrm{pH}$ of 3.3. These two subpopulations might reflect a different progress in cytoplasmic acidification of $621 \mathrm{H}$ cells coping with $\mathrm{pH} 3.3$ in the stationary phase. After resuspension in fresh medium with $\mathrm{pH} 6, \mathrm{mNG}$ fluorescence was recovered and the two subpopulations merged into a single population. In strain BP.6, which is unable to oxidize Larabinose, flow cytometry revealed that the acidification of the medium from $\mathrm{pH} 6$ to 4.4 had only a marginal effect on $\mathrm{mNG}$ fluorescence. As the studies with isolated $\mathrm{mNG}$ demonstrated a strong decrease in fluorescence at $\mathrm{pH} 4.4$ (Steiert et al. 2018), this result indicates that the intracellular $\mathrm{pH}$ in BP.6 cells must be higher than that in $621 \mathrm{H}$ cells. Bacteria have evolved various mechanisms for $\mathrm{pH}$ homeostasis in order to maintain the cytoplasmic $\mathrm{pH}$ in a range that enables survival and growth (reviewed in, for example, Baker-Austin and Dopson 2007; Follmann et al. 2009; Krulwich et al. 2011). For G. oxydans, the mechanisms of $\mathrm{pH}$ homeostasis have not yet been studied. We previously compared global gene expression of G. oxydans $621 \mathrm{H}$ cells grown at $\mathrm{pH} 4$ and at $\mathrm{pH} 6$ and observed 35 genes which were upregulated at $\mathrm{pH} 4$ more than twofold and 37 genes that were downregulated more than twofold (Hanke et al. 2012). Obvious mechanisms for $\mathrm{pH}$ homeostasis could not be deduced from these data. In summary, the comparison of $\mathrm{mNG}$ fluorescence in strains $621 \mathrm{H}$ and BP.6 suggested that G. oxydans is well able to perform reasonable $\mathrm{pH}$ homeostasis at $\mathrm{pH} 4.4$ and less able at $\mathrm{pH}$ 3.3. However, when maintaining the medium at $\mathrm{pH} 6$, e.g., by cultivation of the cells with $\mathrm{pH}$ control, the acidification due to L-arabinose oxidation can be avoided also in $G$. oxydans $621 \mathrm{H}$, preserving the activity of proteins synthesized under the control of $\mathrm{P}_{B A D}$. Together, our results demonstrate the functionality and potential of L-arabinose-inducible gene expression as a tool for G. oxydans and possibly also for other AAB.

Acknowledgments We are grateful to Lion Flachbart for providing the reporter mNeonGreen and for helpful discussions. We also thank Nick Wierckx or helpful discussion and Armin Ehrenreich for kindly providing G. oxydans strain BP.6 carrying multiple deletions of $\mathrm{mDH}$. For technical support, we thank Sabrina Derksen.

Availability of data and material The microarray data are accessible in NCBI's Gene Expression Omnibus through accession number GSE151596.

Authors' contributions PMF and TL selected the reporters and constructed the plasmids. PMF carried out all growth experiments to test strains with and without constructs and performed the data analysis. JG performed the GC-TOF-MS and data analysis. PMF and CS performed the FACS analysis and analyzed the data. PMF and MO performed the DASbox cultivations. TP designed and supervised the study. PMF, MB, and TP wrote the manuscript. All authors read and approved the final manuscript.

Funding Open Access funding enabled and organized by Projekt DEAL. We are grateful to the Federal Ministry of Education and Research (BMBF) for generous financial support of the project IMPRES (031B0370B). The funding organization did not influence the design of the study or collection, analysis, and interpretation of data, or writing the manuscript.

\section{Compliance with ethical standards}

Conflicts of interest The authors declare that they have no conflict of interest.

Ethical statement This article does not contain any studies with human participants or animals performed by any of the authors.

Open Access This article is licensed under a Creative Commons Attribution 4.0 International License, which permits use, sharing, adaptation, distribution and reproduction in any medium or format, as long as you give appropriate credit to the original author(s) and the source, provide a link to the Creative Commons licence, and indicate if changes were made. The images or other third party material in this article are included in the article's Creative Commons licence, unless indicated otherwise in a credit line to the material. If material is not included in the article's Creative Commons licence and your intended use is not permitted by statutory regulation or exceeds the permitted use, you will need to obtain permission directly from the copyright holder. To view a copy of this licence, visit http://creativecommons.org/licenses/by/4.0/.

\section{References}

Ameyama M, Shinagawa E, Matsushita K, Adachi O (1981) D-fructose dehydrogenase of Gluconobacter industrius: purification, characterization, and application to enzymatic microdetermination of D-fructose. J Bacteriol 145(2):814-823

Baker-Austin C, Dopson M (2007) Life in acid: pH homeostasis in acidophiles. Trends Microbiol 15(4):165-171. https://doi.org/10.1016/j. tim.2007.02.005

Brunelle A, Schleif R (1989) Determining residue-base interactions between AraC-protein and araI DNA. J Mol Biol 209(4):607-622. https://doi.org/10.1016/0022-2836(89)90598-6

Casadaban MJ (1976) Transposition and fusion of the lac genes to selected promoters in Escherichia coli using bacteriophage lambda and Mu. J Mol Biol 104(3):541-555. https://doi.org/10.1016/00222836(76)90119-4

Chen R (2012) Bacterial expression systems for recombinant protein production: E. coli and beyond. Biotechnol Adv 30(5):1102-1107. https://doi.org/10.1016/j.biotechadv.2011.09.013

Connell ND (2001) Expression systems for use in actinomycetes and related organisms. Curr Opin Biotechnol 12(5):446-449. https:// doi.org/10.1016/S0958-1669(00)00243-3

Dilworth MV, Piel MS, Bettaney KE, Ma P, Luo J, Sharples D, Poyner DR, Gross SR, Moncoq K, Henderson PJF, Miroux B, Bill RM (2018) Microbial expression systems for membrane proteins. Methods 147:3-39. https://doi.org/10.1016/j.ymeth.2018.04.009 
Englesberg E (1961) Enzymatic characterization of 17 L-arabinose negative mutants of Escherichia coli. J Bacteriol 81:996-1006

Englesberg E, Anderson RL, Weinberg R, Lee N, Hoffee P, Huttenhauer G, Boyer H (1962) L-Arabinose-sensitive, L-ribulose 5-phosphate 4epimerase-deficient mutants of Escherichia coli. J Bacteriol 84:137146

Evans JC, Mizrahi V (2015) The application of tetracyclineregulated gene expression systems in the validation of novel drug targets in Mycobacterium tuberculosis. Front Microbiol 6:812. https://doi. org/10.3389/fmicb.2015.00812

Florea M, Hagemann H, Santosa G, Abbott J, Micklem CN, SpencerMilnes X, Garcia LD, Paschou D, Lazenbatt C, Kong DZ, Chughtai H, Jensen K, Freemont PS, Kitney R, Reeve B, Ellis T (2016) Engineering control of bacterial cellulose production using a genetic toolkit and a new cellulose-producing strain. Proc Natl Acad Sci 113(24):E3431-E3440. https://doi.org/10.1073/pnas.1522985113

Follmann M, Ochrombel I, Kramer R, Trotschel C, Poetsch A, Ruckert C, Huser A, Persicke M, Seiferling D, Kalinowski J, Marin K (2009) Functional genomics of $\mathrm{pH}$ homeostasis in Corynebacterium glutamicum revealed novel links between $\mathrm{pH}$ response, oxidative stress, iron homeostasis and methionine synthesis. BMC Genomics 10. https://doi.org/10.1186/1471-2164-10-621

Forstner M, Leder L, Mayr LM (2007) Optimization of protein expression systems for modern drug discovery. Expert Rev Proteomics 4(1):67-78. https://doi.org/10.1586/14789450.4.1.67

Gibson DG, Young L, Chuang RY, Venter JC, Hutchison CA, Smith HO (2009) Enzymatic assembly of DNA molecules up to several hundred kilobases. Nat Methods 6(5):343-U41. https://doi.org/10.1038/ Nmeth. 1318

Gruber S, Schwab H, Koefinger P (2015) Versatile plasmid-based expression systems for Gram-negative bacteria-General essentials exemplified with the bacterium Ralstonia eutropha H16. New Biotechnol 32(6):552-558. https://doi.org/10.1016/j.nbt.2015.03. 015

Gupta A, Singh VK, Qazi GN, Kumar A (2001) Gluconobacter oxydans: its biotechnological applications. J Mol Microbiol Biotechnol 3(3): $445-456$

Guzman LM, Belin D, Carson MJ, Beckwith J (1995) Tight regulation, modulation, and high-level expression by vectors containing the arabinose $\mathrm{P}_{B A D}$ promoter. J Bacteriol 177(14):4121-4130. https:// doi.org/10.1128/jb.177.14.4121-4130.1995

Hanahan D (1983) Studies on transformation of Escherichia coli with plasmids. J Mol Biol 166(4):557-580

Hanke T, Richhardt J, Polen T, Sahm H, Bringer S, Bott M (2012) Influence of oxygen limitation, absence of the cytochrome bc(1) complex and low $\mathrm{pH}$ on global gene expression in Gluconobacter oxydans $621 \mathrm{H}$ using DNA microarray technology. J Biotechnol 157(3):359-372. https://doi.org/10.1016/j.jbiotec.2011.12.020

Hekmat D, Bauer R, Fricke J (2003) Optimization of the microbial synthesis of dihydroxyacetone from glycerol with Gluconobacter oxydans. Bioprocess Biosyst Eng 26(2):109-116. https://doi.org/ 10.1007/s00449-003-0338-9

Hentschel E, Will C, Mustafi N, Burkovski A, Rehm N, Frunzke J (2013) Destabilized eYFP variants for dynamic gene expression studies in Corynebacterium glutamicum. Microb Biotechnol 6(2):196-201. https://doi.org/10.1111/j.1751-7915.2012.00360.x

Hölscher T, Weinert-Sepalage D, Görisch H (2007) Identification of membrane-bound quinoprotein inositol dehydrogenase in Gluconobacter oxydans ATCC 621H. Microbiology 153(Pt 2): 499-506. https://doi.org/10.1099/mic.0.2006/002196-0

Jefferson RA, Burgess SM, Hirsh D (1986) Beta-glucuronidase from Escherichia coli as a gene-fusion marker. Proc Natl Acad Sci 83(22):8447-8451. https://doi.org/10.1073/pnas.83.22.8447

Kallnik V, Meyer M, Deppenmeier U, Schweiger P (2010) Construction of expression vectors for protein production in Gluconobacter oxydans. J Biotechnol 150(4):460-465. https://doi.org/10.1016/j. jbiotec.2010.10.069

Khlebnikov A, Datsenko KA, Skaug T, Wanner BL, Keasling JD (2001) Homogeneous expression of the $\mathrm{P}(\mathrm{BAD})$ promoter in Escherichia coli by constitutive expression of the low-affinity high-capacity AraE transporter. Microbiology 147(Pt 12):3241-3247. https://doi. org/10.1099/00221287-147-12-3241

Kiefler I, Bringer S, Bott M (2015) SdhE-dependent formation of a functional Acetobacter pasteurianus succinate dehydrogenase in Gluconobacter oxydans-a first step toward a complete tricarboxylic acid cycle. Appl Microbiol Biotechnol 99(21):9147-9160. https:// doi.org/10.1007/s00253-015-6972-8

Kiefler I, Bringer S, Bott M (2017) Metabolic engineering of Gluconobacter oxydans $621 \mathrm{H}$ for increased biomass yield. Appl Microbiol Biotechnol 101(13):5453-5467. https://doi.org/10.1007/ s00253-017-8308-3

Korner H, Sofia HJ, Zumft WG (2003) Phylogeny of the bacterial superfamily of Crp-Fnr transcription regulators: exploiting the metabolic spectrum by controlling alternative gene programs. FEMS Microbiol Rev 27(5):559-592. https://doi.org/10.1016/S01686445(03)00066-4

Kovach ME, Elzer PH, Hill DS, Robertson GT, Farris MA, Roop RM 2nd, Peterson KM (1995) Four new derivatives of the broad-hostrange cloning vector $\mathrm{pBBR} 1 \mathrm{MCS}$, carrying different antibioticresistance cassettes. Gene 166(1):175-176. https://doi.org/10.1016/ 0378-1119(95)00584-1

Kranz A, Vogel A, Degner U, Kiefler I, Bott M, Usadel B, Polen T (2017) High precision genome sequencing of engineered Gluconobacter oxydans $621 \mathrm{H}$ by combining long nanopore and short accurate Illumina reads. J Biotechnol 258:197-205. https://doi.org/10.1016/ j.jbiotec.2017.04.016

Kranz A, Steinmann A, Degner U, Mengus-Kaya A, Matamouros S, Bott M, Polen T (2018) Global mRNA decay and 23S rRNA fragmentation in Gluconobacter oxydans 621H. BMC Genomics 19(1):753. https://doi.org/10.1186/s12864-018-5111-1

Krulwich TA, Sachs G, Padan E (2011) Molecular aspects of bacterial pH sensing and homeostasis. Nat Rev Microbiol 9(5):330-343. https:// doi.org/10.1038/nrmicro2549

Mamlouk D, Gullo M (2013) Acetic acid bacteria: physiology and carbon sources oxidation. Indian J Microbiol 53(4):377-384. https://doi. org/10.1007/s12088-013-0414-Z

Merfort M, Herrmann U, Bringer-Meyer S, Sahm H (2006a) High-yield 5-keto-D-gluconic acid formation is mediated by soluble and membrane-bound gluconate-5-dehydrogenases of Gluconobacter oxydans. Appl Microbiol Biotechnol 73(2):443-451. https://doi. org/10.1007/s00253-006-0467-6

Merfort M, Herrmann U, Ha SW, Elfari M, Bringer-Meyer S, Gorisch H, Sahm H (2006b) Modification of the membrane-bound glucose oxidation system in Gluconobacter oxydans significantly increases gluconate and 5-keto-D-gluconic acid accumulation. Biotechnol J 1(5):556-563. https://doi.org/10.1002/biot.200600032

Meyer M, Schweiger P, Deppenmeier U (2013) Effects of membranebound glucose dehydrogenase overproduction on the respiratory chain of Gluconobacter oxydans. Appl Microbiol Biotechnol 97(8):3457-3466. https://doi.org/10.1007/s00253-012-4265-z

Mientus M, Kostner D, Peters B, Liebl W, Ehrenreich A (2017) Characterization of membrane-bound dehydrogenases of Gluconobacter oxydans $621 \mathrm{H}$ using a new system for their functional expression. Appl Microbiol Biotechnol 101(8):3189-3200. https://doi.org/10.1007/s00253-016-8069-4

Miller JH (1992) A short course in bacterial genetics. Cold Spring Harbor Laboratory Press, Cold Spring Harbor

Narayanan N, Xu Y, Chou CP (2006) High-level gene expression for recombinant penicillin acylase production using the $a r a B$ promoter system in Escherichia coli. Biotechnol Prog 22(6):1518-1523. https://doi.org/10.1021/bp060135u 
Paczia N, Nilgen A, Lehmann T, Gatgens J, Wiechert W, Noack S (2012) Extensive exometabolome analysis reveals extended overflow metabolism in various microorganisms. Microb Cell Factories 11:122. https://doi.org/10.1186/1475-2859-11-122

Pappenberger G, Hohmann HP (2014) Industrial production of L-ascorbic acid (vitamin C) and D-isoascorbic acid. Adv Biochem Eng Biotechnol 143:143-188. https://doi.org/10.1007/10_2013 243

Parachin NS, Mulder KC, Viana AAB, Dias SC, Franco OL (2012) Expression systems for heterologous production of antimicrobial peptides. Peptides 38(2):446-456. https://doi.org/10.1016/j. peptides.2012.09.020

Peters B, Mientus M, Kostner D, Junker A, Liebl W, Ehrenreich A (2013) Characterization of membrane-bound dehydrogenases from Gluconobacter oxydans $621 \mathrm{H}$ via whole-cell activity assays using multideletion strains. Appl Microbiol Biotechnol 97(14):63976412. https://doi.org/10.1007/s00253-013-4824-y

Prust C, Hoffmeister M, Liesegang H, Wiezer A, Fricke WF, Ehrenreich A, Gottschalk G, Deppenmeier U (2005) Complete genome sequence of the acetic acid bacterium Gluconobacter oxydans. Nat Biotechnol 23(2):195-200. https://doi.org/10.1038/nbt1062

Saito Y, Ishii Y, Hayashi H, Imao Y, Akashi T, Yoshikawa K, Noguchi Y, Soeda S, Yoshida M, Niwa M, Hosoda J, Shimomura K (1997) Cloning of genes coding for L-sorbose and L-sorbosone dehydrogenases from Gluconobacter oxydans and microbial production of 2keto-L-gulonate, a precursor of L-ascorbic acid, in a recombinant G. oxydans strain. Appl Environ Microbiol 63(2):454-460

Sambrook J, Fritsch EF, Maniatis T (1989) Molecular cloning: a laboratory manual. Cold Spring Harbor Laboratory Press, Cold Spring Harbor

Schleif R (2010) AraC protein, regulation of the L-arabinose operon in Escherichia coli, and the light switch mechanism of AraC action. FEMS Microbiol Rev 34(5):779-796. https://doi.org/10.1111/j. 1574-6976.2010.00226.x

Schleyer U, Bringer-Meyer S, Sahm H (2008) An easy cloning and expression vector system for Gluconobacter oxydans. Int J Food Microbiol 125(1):91-95. https://doi.org/10.1016/j.ijfoodmicro. 2007.04.016

Schnappinger D, Ehrt S (2014) Regulated expression systems for mycobacteria and their applications. Microbiol Spectr 2(1). https:// doi.org/10.1128/microbiolspec.MGM2-0018-2013

Shaner NC, Lambert GG, Chammas A, Ni Y, Cranfill PJ, Baird MA, Sell BR, Allen JR, Day RN, Israelsson M, Davidson MW, Wang J (2013) A bright monomeric green fluorescent protein derived from
Branchiostoma lanceolatum. Nat Methods 10(5):407-409. https:// doi.org/10.1038/nmeth.2413

Simon R, Priefer U, Pühler A (1983) A broad host range mobilization system for in vivo genetic-engineering - Transposon mutagenesis in Gram-negative bacteria. Bioresour Technol 1(9):784-791. https:// doi.org/10.1038/nbt1183-784

Soisson SM, MacDougall-Shackleton B, Schleif R, Wolberger C (1997) Structural basis for ligand-regulated oligomerization of AraC. Science 276(5311):421-425. https://doi.org/10.1126/science.276. 5311.421

Steiert F, Petrov EP, Schultz P, Schwille P, Weidemann T (2018) Photophysical behavior of mNeonGreen, an evolutionarily distant green fluorescent protein. Biophys J 114(10):2419-2431. https:// doi.org/10.1016/j.bpj.2018.04.013

Teh MY, Ooi KH, Teo SXD, Bin Mansoor ME, Lim WZS, Tan MH (2019) An expanded synthetic biology toolkit for gene expression control in Acetobacteraceae. ACS Synth Biol 8(4):708-723. https:// doi.org/10.1021/j.acssynbio.8b00168

Terpe K (2006) Overview of bacterial expression systems for heterologous protein production: from molecular and biochemical fundamentals to commercial systems. Appl Microbiol Biotechnol 72(2): 211-222. https://doi.org/10.1007/s00253-006-0465-8

Tkac J, Navratil M, Sturdik E, Gemeiner P (2001) Monitoring of dihydroxyacetone production during oxidation of glycerol by immobilized Gluconobacter oxydans cells with an enzyme biosensor. Enzym Microb Technol 28(4-5):383-388

Tonouchi N, Sugiyama M, Yokozeki K (2003) Construction of a vector plasmid for use in Gluconobacter oxydans. Biosci Biotechnol Biochem 67(1):211-213. https://doi.org/10.1271/bbb.67.211

Valero F (2012) Heterologous expression systems for lipases: A review. Methods Mol Biol 861:161-178. https://doi.org/10.1007/978-161779-600-5 11

Wang EX, Ding MZ, Ma Q, Dong XT, Yuan YJ (2016) Reorganization of a synthetic microbial consortium for one-step vitamin C fermentation. Microb Cell Factories 15:21. https://doi.org/10.1186/s12934016-0418-6

Zhang L, Lin JP, Ma YS, Wei DZ, Sun M (2010) Construction of a novel shuttle vector for use in Gluconobacter oxydans. Mol Biotechnol 46(3):227-233. https://doi.org/10.1007/s12033-010-9293-2

Publisher's note Springer Nature remains neutral with regard to jurisdictional claims in published maps and institutional affiliations. 